\title{
PREDICTION OF MONSOON RAINFALL AND RIVER DISCHARGE ON I5-30-DAY TIME SCALES
}

\author{
by Peter J. Webster and Carlos Hoyos
}

\section{A new physically based prediction scheme for 20-30-day variability shows promise in monsoon regions for agricultural planning, disaster mitigation, and flood forecasting.}

D uring the summer of 2002, drought conditions persisted over India from mid-June to mid-July following a later-than-average arrival of seasonal monsoon rain. By the end of that summer, the average summer Indian rainfall totaled $711 \mathrm{~mm}$ or 19\% below normal. With the exception of the area near the foothills of the Himalayas in the very north of India, where above-average rainfall occurred, most of India was in deficit, with the state of Rajasthan $64 \%$ below normal. Figure 1 provides a geographical reference for the locations discussed in the text. The summer of 2002 was the sixth driest in $130 \mathrm{yr}$ (Table 1).

AFFILIATIONS: WEBSTER AND HOYOS-Schools of Earth and Atmospheric Sciences and Civil and Environmental Engineering, Georgia Institute of Technology, Atlanta, Georgia CORRESPONDING AUTHOR: Dr. Peter J. Webster, Environmental Science and Technology Building, 3 I I Ferst Avenue, Atlanta, GA 30332-0340

E-mail: pjw@eas.gatech.edu

DOI:I0.1 I75/BAMS-85-II-I745

In final form II May 2004

(C2004 American Meteorological Society
The failure of the 2002 monsoon rains was not anticipated. The official Indian Meteorological Department seasonal outlook issued in mid-April called for an essentially normal monsoon with seasonal rains about $1 \%$ lower than normal. Other forecasts suggested similar outcomes. For example, predictions by the International Research Institute for Climate (IRI) and the European Centre for Medium-Range Weather Forecasts (ECMWF) made in the spring for the 2002 June-August period suggested slightly below-average precipitation in the south of India but normal precipitation elsewhere (see http://iri.columbia.edu/climate/ forecast and www.ecmwf.int/products/forecasts). The effects of the midseasonal drought were disastrous to India's agrarian economy, especially since the drought occurred early in the monsoon season when agriculture is at its most susceptible stage. The severe reduction in agricultural productivity resulted in hardship and suffering for millions of people and a significant economic loss to the country. Only stores of rice accumulated over a period of years by the government of India prevented an even greater disaster.

Figures $2 \mathrm{a}$ and $2 \mathrm{~b}$ show precipitation time series averaged over central India for the period 1986 through 
(a)

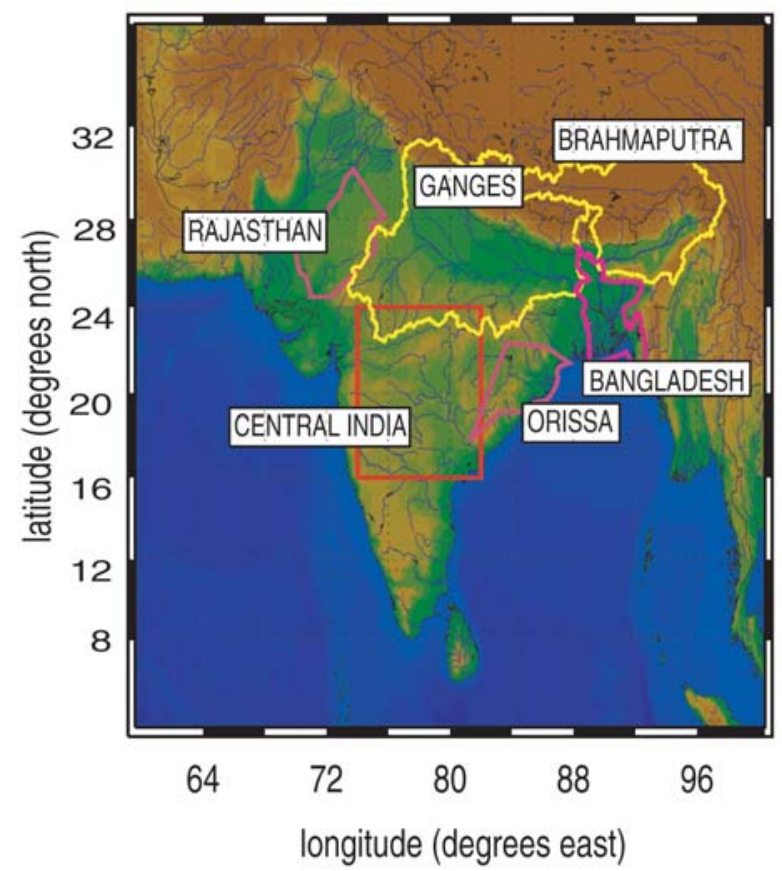

(b)

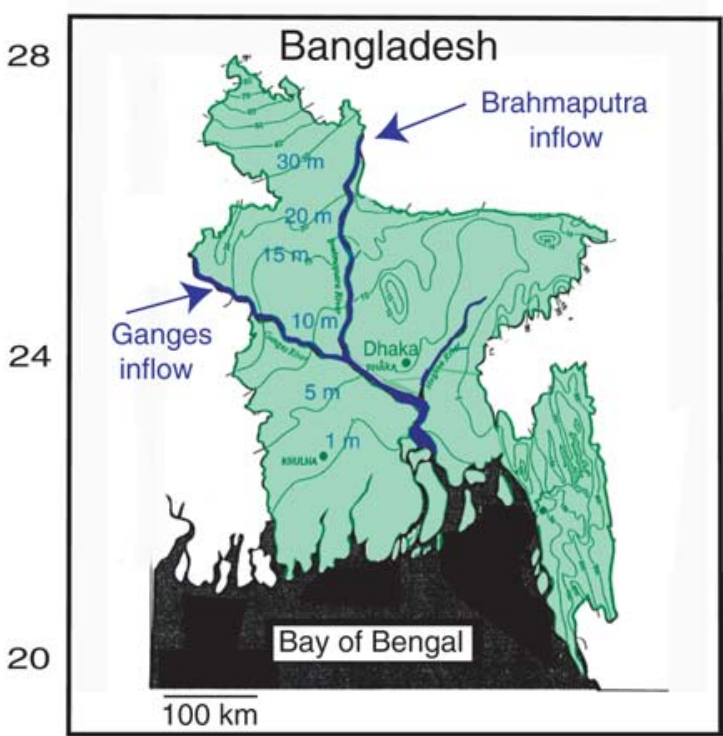

88
90

92

longitude (degrees east)

FIG. I. Geography of locations discussed in the text. (a) The catchment areas of the Brahmaputra and Ganges Rivers are outlined in yellow; the Indian states of Orissa and Rajasthan and the country of Bangladesh are outlined in red. (b) Detailed map of Bangladesh and the entrance points of the Brahamputra and Ganges Rivers into the country. Isopleths show elevation above mean sea level $(\mathrm{m})$.

TABLE I. Years of mean seasonal rainfall deficiency $>10 \%$ below average during the last $130 \mathrm{yr}$.

Rainfall is averaged over the entire Indian subcontinent. The summer of $\mathbf{2 0 0 2}$ was the fifth lowest on record. Data from Institute of Tropical Meteorology, Pune, India, courtesy of Dr. R. Kumar Kolli available online at "Monsoon on Line" www.met.rdg.ac.uk.cag/MOL.

\begin{tabular}{|c|c|c|c|c|c|}
\hline Year & $\%$ & Year & $\%$ & Year & $\%$ \\
\hline 1873 & -11 & 1920 & -15 & 1972 & -24 \\
1877 & -30 & 1928 & -10 & 1974 & -12 \\
1899 & -26 & 1941 & -13 & 1979 & -15 \\
1901 & -15 & 1951 & -17 & 1982 & -13 \\
1905 & -16 & 1965 & -11 & 1985 & -11 \\
1910 & -13 & 1966 & -23 & 1986 & -13 \\
1918 & -24 & 1968 & -12 & 1987 & -17 \\
& \multicolumn{7}{|c}{ Mean summer rainfall: $835 \mathrm{~mm}$. Standard deviation: $85 \mathrm{~mm}}$. \\
\hline
\end{tabular}

2002 and details of the rainfall distribution for the 4-yr period of 1999-2002, respectively. The climatological 103-yr-averaged summer rainfall is superim- posed. Estimates of rainfall come from the Geostationary Operational Environmental Satellite (GOES) Precipitation Index (GPI) product (Arkin and Meisner 1987; Joyce and Arkin 1997). Deficits in summer rainfall of similar magnitudes to that of 2002 are relatively rare. A comparison between the long-term mean annual cycle of rainfall and the rainfall in 1999-2002 (Fig. 2b) underlines three important characteristics of the south Asian monsoon. First, the mean seasonal cycle is smooth, with rainfall starting sometime in late May, reaching a maximum in July, and then slowly decreasing through September. During this period, $80 \%$ of India's annual rainfall occurs. Second, the rainfall distribution in any one year is made up of a series of low-frequency sequences of rainy periods ("active" periods) with intervening dry periods (monsoon "breaks") each lasting 10-30 days. The magnitude of the intraseasonal variability is far greater than the magnitude of the interannual variability (e.g., Webster et al. 1998; Waliser et al. 1999). Third, the smoothness of the mean annual cycle of precipitation suggests that there is no preferred time for the large-amplitude active and break periods of the monsoon to occur.

Utility of seasonal forecasts of all-India rainfall. Prediction of the mean seasonal Indian monsoon rainfall has a long 
history. For the most part, prediction has employed empirical methods. The most common predictand has been the El Niño-Southern Oscillation (ENSO) phenomenon, winter and springtime snowfall over Eurasia, and the sea surface temperature (SST) variability in the Indian Ocean and the northwest equatorial $\mathrm{Pa}$ cific Ocean. Overall, about $30 \%$ of the variance can be explained by ENSO indices (e.g., Shukla and Paolino 1983; Shukla and Mooley 1987; Shukla 1987), with El Niño normally associated with below-average summer Indian precipitation and La Niña with above-average summer rains. Early promise of a strong relationship between Eurasian snowfall and Indian summer rainfall (e.g., Hahn and Shukla 1976; Dickson 1984) has waned under more exacting scrutiny (Bamzai and Shukla 1999). Empirical schemes involving other factors such as Indian Ocean SSTs are discussed in Hastenrath (1986, 1987), Harzallah and Sadourny (1997), and Clark et al. (2000). The common feature of all of these schemes is that they tend to wax and wane on interdecadal time scales (Torrence and Webster 1999). The reason for the variability of predictability between ENSO and the monsoon is not under-

stood. It may stem from subtle relationships between monsoon strength and Pacific SST, because some physical processes have been ignored that may occasionally interfere with monsoon-ENSO connections, or because of the interference of stochastic events.

Let us assume, for the sake of argument, that forecasts of the seasonally averaged rainfall over India are

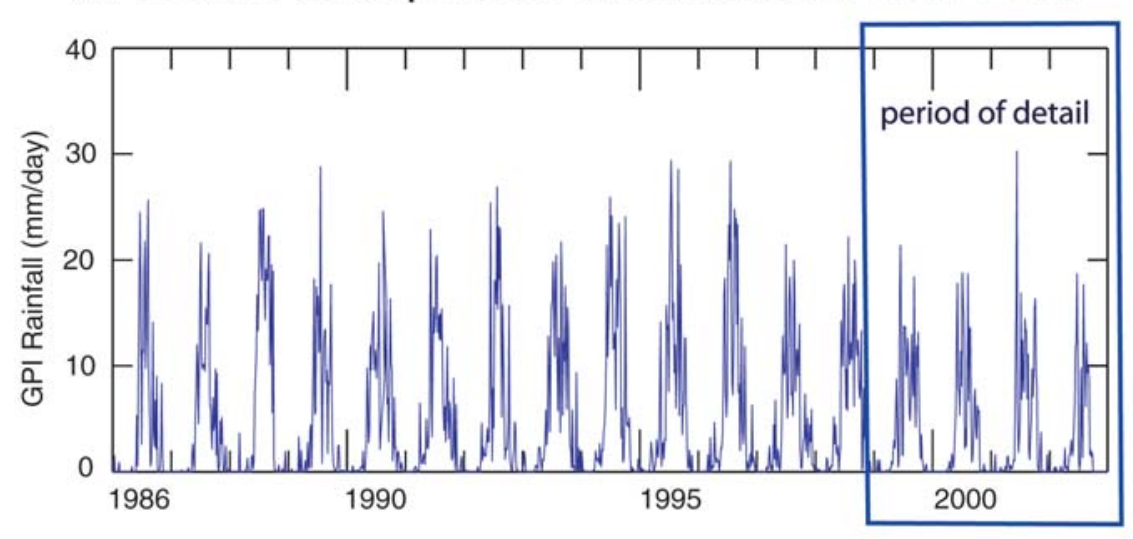

(b) Central India pentad GPI rainfall for 1999-2002
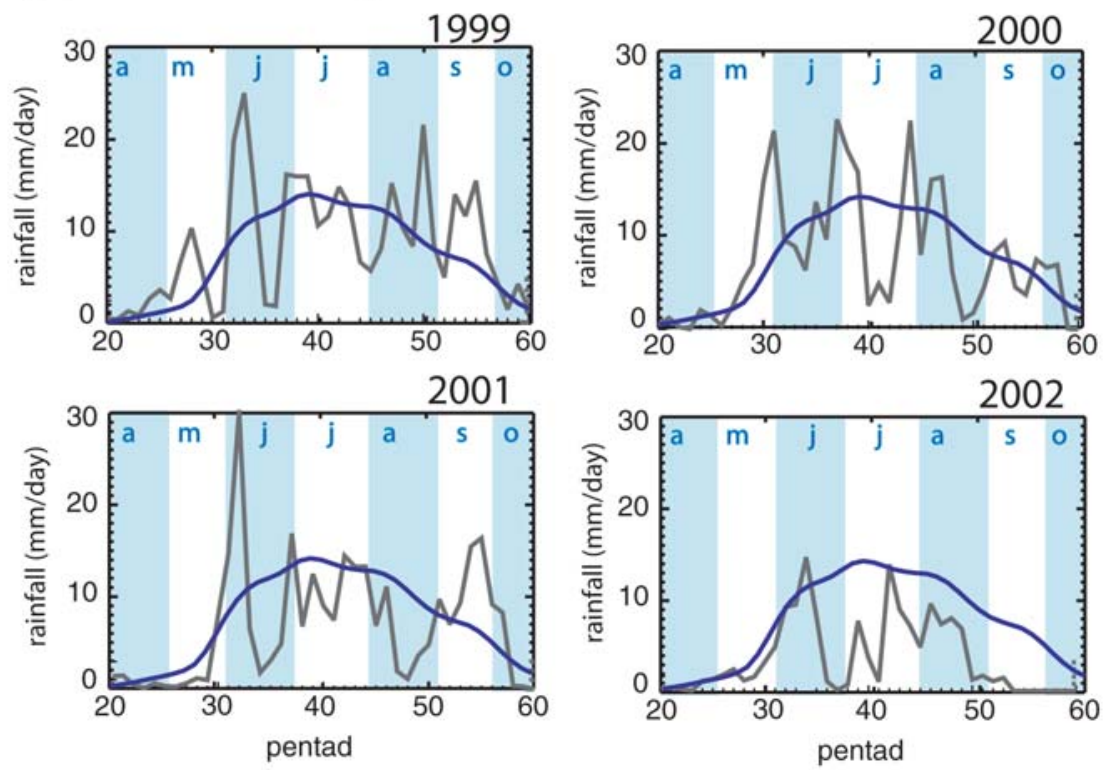

FIG. 2. (a) Satellite-derived GPI averaged over the central India region (see Fig. I) for the period 1986-2002. A large annual cycle is modulated by a relatively small interannual variability. Within each summer season there are large variations of rainfall on time scales of 20-40 days. (b) Details of precipitation for the period 1999-2002 [box in (a)] plotted as average rain rate per pentad. Each year exhibits peaks ("active" monsoon periods) and valleys ("breaks" in the monsoon) of rainfall rate. The smoothness of the long-term averaged annual cycle of precipitation (blue curve) suggests that there is no preferred timing for intraseasonal variability and that it occurs randomly throughout the summer. Light-blue and white background bands indicate months ("a" April, "m" May, etc.). Data from Joyce and Arkin (1997). skillful and that the long-term statistics are robust. How useful would accurate "broad brush" forecasts of the monsoon be to a user community? Figure 3a shows 10-day running means of precipitation in a box in central India for years with regional annual rainfall (i) between $-16 \%$ to $-19 \%$, (ii) between $\pm 2 \%$, and (iii) between $+16 \%$ to $+19 \%$, using data compiled by 
Kripalani et al. (1991), which are described in detail by Singh et al. (1992). The dashed line shows the average annual cycle for each category. Irrespective of the abundance of the rainfall in a season, largeamplitude active and break periods occur irregularly at different times of the season. Figure $3 \mathrm{~b}$ shows three sets of seasonally averaged all-India rainfall distributions: wet (seasonal average $>110 \%$ of average), normal (within $10 \%$ of average), and dry ( $<90 \%$ of average) years. Whereas there is a tendency for the wet and dry categories to contain more districts that have the same sign as the overall anomaly, there are swaths of districts of oppositesigned anomalies across India as well. The three "normal" years [Fig. 3b

(ii)] are even more variable.

In summary, it would be difficult for even a skillful forecast of the all-India seasonal rainfall to provide regional communities with information that could be used effectively in agriculture or water resource management. This does not mean that accurate seasonal forecasts would not be useful. A number of studies (e.g., Gadgil 1996; Webster et al. 1998) have shown that Indian crop yields are negatively correlated with the occurrence of El Niño. Selvaraju (2003) has quantified the effect on Indian agriculture, noting that El Niño costs India about 800 million U.S. dollars (USD), while La Niña provides a gain of some 400 million USD to the national economy. Thus, broadbrush assessments may be useful at the level of national commodity markets.

Utility of intraseasonal monsoon forecasts. It has become increasingly apparent that skillful and timely forecasts of monsoon intraseasonal variability may provide optimal information for regional agriculture and water resource management. For example, in ADPC (2002), which deals with the impact of climate forecasts on agriculture in Bangladesh, it is noted that "the minimum length of a forecast which will allow a farming community to respond and take meaningful remedial actions against either flood or drought is about 10 days. An optimal forecast period is in excess of 3 weeks." WMO (2001) notes that one of the most important problems, especially in monsoon regions, is the forecasting of intraseasonal variability. Gadgil et al. (1999), referring to the impact of active and break periods on groundnut production in India notes, "the occurrence of some climate events such as wet/dry spells have a large impact on the productivity of the crop. Dry spells induce moisture stress ... impacting ... growth and development ... and ... dry/wet spells trigger the growth of pests/diseases/ weeds and hence have an impact on the yield." An immediate application of a forecast of intraseasonal variability would be the "tailoring of operations" discussed by Gadgil et al. (2002), who note further that "an easy option is the choice of a sowing date [which 
(i) $>115 \%$ summer average
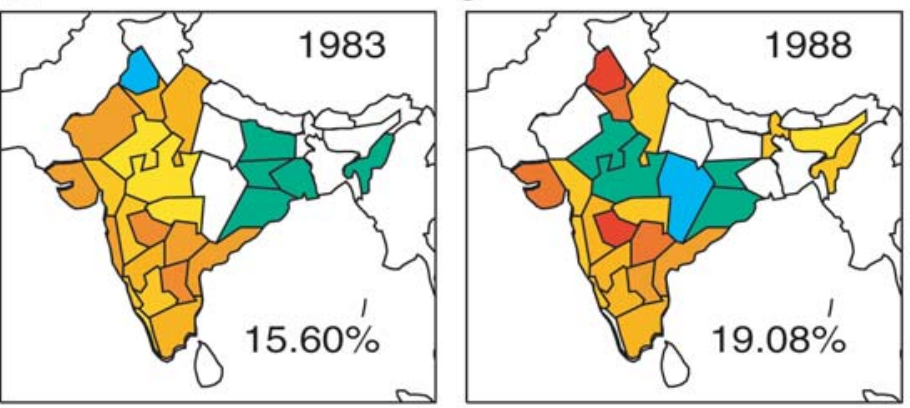

(ii) $98 \%$ to $101 \%$ summer average
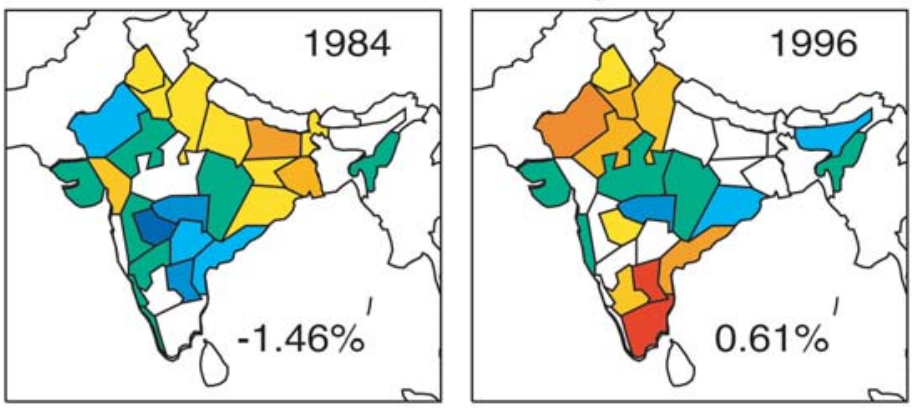

(iii) $<90 \%$ summer average
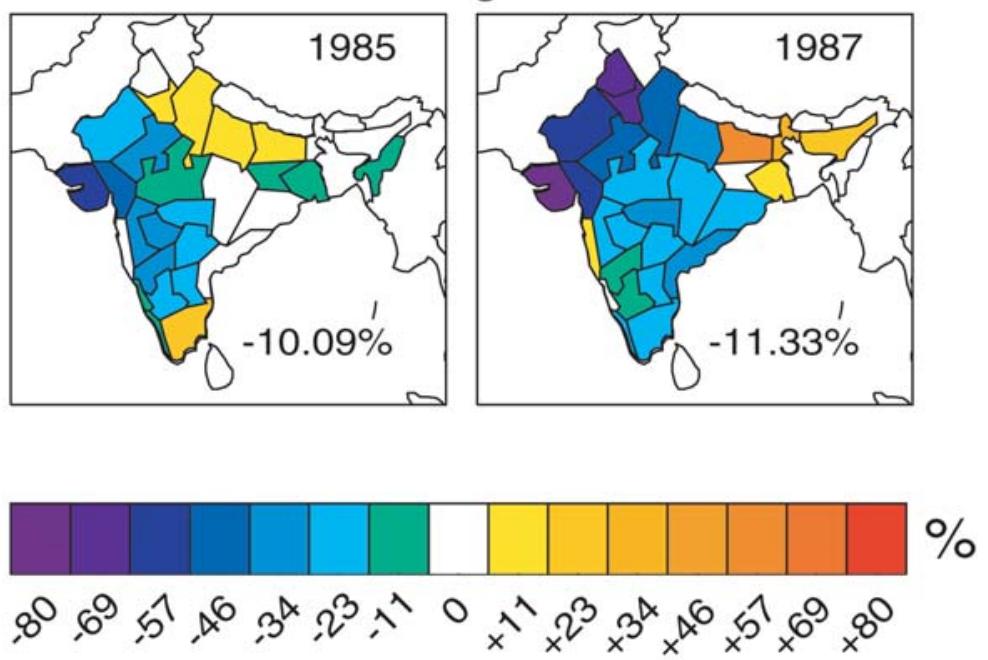

partment on the consequences of the 2002 Indian drought. It was noted that, "Assuming that a prediction of the July drought had been available by the third week of June 2002, and of the revival of the monsoon rains by second week of July 2002, the forecasts would have helped to preserve farm income and ensured food security and reduce relief expenditure by at least $60 \%$ of the present cost (i.e., around 6 billion USD) . . . a 20 -day forecast during monsoon 2002 in India could have mitigated the impacts of the droughts in several parts of India to a significant extent" (Subbiah 2004).

During the last few years, research efforts to understand, simulate, and predict intraseasonal variability has increased substantially. Whereas there has been significant progress, the results of modeling intraseasonal variability have so far been mixed. For example, Slingo et al. (1996) found that only a few of the models studied possessed intraseasonal variance comparable to observations. On the other hand, later studies that concentrated on the boreal summer intraseasonal variability (Sperber et al. 2000, 2001; Waliser et al. 2003a,d) found a variety of responses by different models, some of which possessed greaterthan-observed variability. Despite the intermodel differences in the simulation of the monsoon, the totality of results suggests the potential for the eventual numerical predic-

does] not involve any additional costs but could involve losses if the farmer chooses to skip the first [planting] opportunity and the second does not arise." Gadgil et al. (2002) support their conclusions with data relating sowing date with final yield.

The references above speak to the general issue of the agricultural consequences of forecasts of monsoon variability. But are there specific examples of where skillful intraseasonal forecasts could have made a significant impact such as the midsummer drought in 2002? Potential impact of such forecasts is discussed in a report prepared by the Asian Disaster Preparedness Center (ADPC) for the Indian Agricultural De- tion of the intraseasonal variability (e.g., Waliser et al. 2003b). Earlier innovative modeling work by Krishnamurti et al. (1990, 1992, 1995) will be discussed later. A more complete review of progress in the modeling, simulation, and numerical prediction of intraseasonal variability, plus plans for model improvement and innovative experimentation can be found in Waliser et al. (2003c).

There has been moderate success in empirical prediction of intraseasonal variability. For example, von Storch and Xu (1990) used principal oscillation pattern (POP) techniques to identify and predict largescale intraseasonal features in the Tropics. Anomaly 
correlations between the observed and predicted upper-tropospheric velocity potential fields were about 0.6 after 7 days, which represented a considerable improvement on persistence. Waliser et al. (1999) developed a statistical model using filtered outgoing longwave radiation (OLR) data in the 20-70 day band. Anomaly correlations of 0.9 at 5 days were found but decreased to about 0.5 at 20 days, similar to the results of Wheeler and Weickmann (2001) and Lo and Hendon (2000). Also, Mo (2001), using singular spectral analysis (SSA) and maximum entropy method (MEM) techniques, found regional anomaly correlations as high as 0.6 at 20 days.

It is fair to conclude that the skill of models in simulating and predicting intraseasonal variability will increase in time to the level where useful forecasts will be produced numerically. However, until that time is reached, it seems prudent to continue to develop empirical forecasts in the spirit of von Storch and Xu (1990), Waliser et al. (1999), Lo and Hendon (2000), and Mo (2001), as discussed above.

In this study, we concentrate on the prediction of intraseasonal oscillations in the south Asian monsoon region using a new type of statistical model: a dynamically based Bayesian statistical scheme that combines wavelet analysis and linear regression, which we refer to as the Bayesian wavelet-banding (WB) method. The concept of wavelet banding comes from a scheme developed by Poveda et al. (2001) for hydrological forecasting in Colombia. Predictors are chosen from detailed analyses of monsoon intraseasonal oscillations (MISOs), as described by detailed diagnostic studies. The identification and predictability of the MISO is discussed in the next section. In the section on "Predictands, predictors, and statistical schemes" we describe the new statistical scheme, and in the "Predictions" section we show examples of forecasts in the 15-30-day time range for precipitation over central India and the smaller regions of Orissa and Rajasthan, in addition to Ganges and Brahmaputra River discharge into Bangladesh. In the section "Comparison of skill with other statistical techniques," we compare the skill of a bandedwavelet scheme with other prediction schemes. We conclude with a discussion of how the precipitation forecasts may be used in the agriculture and water resource sectors of the monsoon regions. Finally, in the appendix we show that the choice of physically based predictors is a necessary condition for prediction, whereas for sufficiency, consistent wavelet banding of the predictand and predictors is also needed.

\section{MONSOON INTRASEASONAL VARIABILITY.}

A critical aspect of a physically based empirical scheme is the choice of a set of predictors. To identify these predictors we seek recurrent factors in the morphology of the MISO. We discuss these recurrent features in the following paragraphs.

MISOs are manifestations of the Madden-Julian oscillation (MJO; Madden and Julian 1972) occurring in the boreal summer with maximum amplitude in the Indian Ocean-south Asian region (Madden and Julian 1994). Overall, the MJO is a ubiquitous feature of the tropical atmosphere and is marked by distinct periods of eastward-propagating convection (e.g., Madden and Julian 1994). During the boreal summer, variance resides principally in the 20-40-day spectral band compared to 30-50 days in the boreal winter. Furthermore, the amplitude of the summer oscillation is somewhat smaller than that occurring in the winter (e.g., Hendon and Salby 1996).

The northward extension of equatorial convection to south Asia during summer has been known for over two decades (e.g., Murakami 1976; Yasunari 1979, 1980; Sikka and Gadgil 1980). Five inferences can be made from these early studies: (i) convection is stronger in the eastern Indian Ocean than in the west; (ii) eastern Indian Ocean equatorial convection generally lags western Indian Ocean convection by a number of days, although convection can grow in situ in the eastern Indian Ocean; (iii) a northward extension of convection occurs primarily in the eastern Indian Ocean; (iv) convection over the east equatorial Indian Ocean is out of phase with convection over India; and (v) the northward extensions of convection coincide with the development of active periods of the monsoon over south Asia.

Lawrence and Webster (2002) extended an earlier analysis by Webster et al. (1998) by categorizing and compositing over 58 MISOs in the 24 summers from 1975 to 1999. Composites were based on the existence of a prolonged relative minimum in OLR (i.e., deep convection) in the eastern Indian Ocean $\left(0.5^{\circ} \mathrm{N}, 85\right.$ $90^{\circ} \mathrm{E}$ ) on the 20-80-day time scales [see Lawrence and Webster (2002) for details on compositing strategy]. A regression technique was used similar to that developed by Kiladis and Weickmann (1992). Figure 4 shows composite OLR anomalies identified by this process. Lawrence and Webster (2002) found that about half of the MISOs developed in situ in the eastern Indian Ocean. The rest developed in the western Indian Ocean before propagating eastward at 3$4 \mathrm{~m} \mathrm{~s}^{-1}$ toward the eastern Indian Ocean. All of the events showed distinctive $2 \mathrm{~m} \mathrm{~s}^{-1}$ northward propagation as well as a less extensive southward extension 
into the Southern Hemisphere. MISOs developing in situ (right-hand panels) do not appear to propagate eastward into the Pacific Ocean. The composite patterns shown in Fig. 4 were essentially independent of the base location in the Indian Ocean or south Asian region (Lawrence and Webster 2002), indicating that the dominant physical processes determining convection in the Indian Ocean-south Asian region were essentially the same. A recent study using satellite data (Wang et al. 2004, manuscript submitted to Geophys. Res. Lett.) ties together the features shown in Fig. 4 in the context of a basinwide selfinduction process of the coupled ocean-atmosphere system.

The reason for the poleward extension of convection into both hemispheres in the eastern Indian Ocean is not known except that the propagation occurs as a trailing Rossby wave behind the eastward convectively coupled Kelvin-Rossby packet (Wang and Rui 1997). It is noted, however, that because of the proximity of the heated continent to the north (e.g., Webster 1983) and the ensuing meridional cross-equatorial pressure gradient it is possible for low-frequency instabilities to be produced as suggested by Tomas and Webster (1997), Krishnakumar and Lau (1998), and Tomas et al. (1999). In any event, the northwardmoving branch of the bifurcation becomes the active period of the monsoon as it moves northward through the Bay of Bengal from where it extends across central India and south Asia and into the western Pacific Ocean. Prior to the bifurcation and when convection is a maximum in the east Indian Ocean along the equator (day 0 of the composite) the Indian subcontinent is generally dry and in a break phase.

Finally, there appears to be some evidence that there is a strong connection between the MISO and interannual variability. For example, Ferranti et al.
(1997) noted that EOF patterns of interannual variations were essentially the same as those for intraseasonal variations. In accord with Hendon et al. (1999) for the north Australian summer monsoon, Lawrence and Webster (2001) noted that fewer MISOs occur in a strong monsoon and more occur with a weak monsoon and that in El Niño periods there is a tendency for there to be greater intraseasonal activity. Palmer (1994), Webster et al. (1998), and Goswami and Mohan (2001) came to the common conclusion that the MISO was the fundamental building block of interannual variability that might explain the common patterns shared by intraseasonal and interannual variability.

\section{PREDICTANDS, PREDICTORS, AND STA-} TISTICAL SCHEMES. Predictands and predictors. The predictand can be any factor for which there exists a long-term time series and is usually directly applicable to some problem. Whether or not the predictand possesses predictability depends, in the 


\begin{tabular}{|c|c|c|c|}
\hline \multicolumn{4}{|c|}{ Predictors } \\
\hline No. & Field & Region & Data source \\
\hline I & Arabian Sea $10-m$ zonal wind & $10^{\circ}-15^{\circ} \mathrm{N}, 65^{\circ}-75^{\circ} \mathrm{E}$ & NCEP* \\
\hline 2 & Central India OLR & $15^{\circ}-25^{\circ} \mathrm{N}, 70^{\circ}-85^{\circ} \mathrm{E}$ & NOAA** \\
\hline 3 & Central India soil moisture & $15^{\circ}-25^{\circ} \mathrm{N}, 70^{\circ}-85^{\circ} \mathrm{E}$ & NCEP* \\
\hline 4 & Equatorial Indian Ocean 200-mb zonal wind & $5^{\circ} \mathrm{S}-5^{\circ} \mathrm{N}, 70^{\circ}-85^{\circ} \mathrm{E}$ & NCEP* \\
\hline 5 & Somalia jet $925-\mathrm{mb}$ meridional wind & $2^{\circ} \mathrm{S}-8^{\circ} \mathrm{N}, 65^{\circ}-75^{\circ} \mathrm{E}$ & NCEP* \\
\hline 6 & Arabian Sea 10-m meridional wind & $10^{\circ}-15^{\circ} \mathrm{N}, 65^{\circ}-75^{\circ} \mathrm{E}$ & NCEP* \\
\hline 7 & Central India surface pressure & $15^{\circ}-25^{\circ} \mathrm{N}, 70^{\circ}-85^{\circ} \mathrm{E}$ & NCEP* \\
\hline 8 & Equatorial Indian Ocean $10-\mathrm{m}$ zonal wind & $5^{\circ} \mathrm{S}-5^{\circ} \mathrm{N}, 70^{\circ}-85^{\circ} \mathrm{E}$ & NCEP* \\
\hline 9 & Equatorial Indian Ocean OLR & $5^{\circ} \mathrm{S}-5^{\circ} \mathrm{N}, 70^{\circ}-85^{\circ} \mathrm{E}$ & NOAA** \\
\hline 10 & Tropical 200-mb easterly jet index & $20^{\circ}-30^{\circ} \mathrm{N}, 70^{\circ}-100^{\circ} \mathrm{E}$ & NCEP* \\
\hline
\end{tabular}

* National Centers for Environmental Prediction-National Center for Atmospheric Research (NCEP-NCAR) reanalysis data have been obtained from www.cdc.noaa.gov/cdc/reanalysis/. The data are described by Kalnay et al. (1996).

**Estimates of OLR from the NOAA polar-orbiting satellites (Gruber and Krueger 1984; Liebmann and Smith 1996).

present context, on the degree to which it is determined by the MISO. Examples of predictands used in this study are rainfall over the central India region (Fig. 2a), river discharge of the Brahmaputra and the Ganges at the borders of India and Bangladesh (see Fig. 9) and the rainfall in the Indian states of Orissa and Rajasthan (see Fig. 10). Since in situ precipitation measurements are difficult to obtain in a timely manner, we use satellite precipitation estimates such as GPI that have been produced in pentad since 1986. The government of Bangladesh has made daily river discharge data for the Bahmaputra and the Ganges available from 1986 to the present.

There are two philosophies used for choosing predictors: "frequentist" (von Storch and Zwiers 1999) and Bayesian (Leonard and Hsu 1999). In the former technique, predictors are chosen principally from their statistical relationship with the predictand. For example, Walker's initial efforts to predict monsoon variability (e.g., Walker 1923) came from the examination of a wide range of climate parameters that has seemingly no apparent physical relationship. Ultimately, this a posteriori technique broken down for prolonged periods (e.g., Kumar et al. 1999; Torrence and Webster 1999). The second technique chooses predictors based on their physical relationship with the predictand. Simply, the predictors are chosen in an a priori fashion based on the physics of the phenomenon one is trying to predict. Here the predictors become the Bayesian priors of the system.

Table 2 lists the predictors used in the study together with the geographic domain where they were calculated and the source of the data used in the computation. As the scheme is used in experimental operational mode in the Climate Forecasting Applications in Bangladesh (CFAB) project, the data must be easily accessible and readily available. Thus we choose the two National Oceanic and Atmospheric Administration (NOAA) sites listed in the table. There are 10 predictors in all, each of which identifies a critical aspect of the MISO phenomena. Predictors 2 and 9 characterize the large-scale convection over central India and the equatorial Indian Ocean, respectively. The dashed-line boxes on the composites shown in Fig. 4 indicate the strategic location of the geographic domains. The lowertropospheric basinwide wind field is characterized by predictors 1 and 6 (Arabian sea surface zonal and meridional wind components), 5 (strength of the 925-mb Somalia jet), and 8 (equatorial central Indian Ocean zonal wind component). Predictor 4 describes the equatorial upper-tropospheric wind structure. Predictor 10 is an index depicting the location where the equatorial upper-tropospheric westerlies become easterlies at $200 \mathrm{mb}$. During the evolution of a MISO the upper-tropospheric easterlies change their inten- 
sity and location. Predictor 10 depicts these changes. Predictor 7 provides information about the location and intensity of the monsoon trough. The central India soil moisture is included following its suggested importance in the timing of intraseasonal oscillations by Webster (1983).

Note that SST is not used as a predictor despite its clear significance. Webster et al. (1998) and Lawrence and Webster (2002) found a $0.5^{\circ} \mathrm{C}$ cooling with the advent of the disturbed phase of the MISO. These estimates come from the Reynold's SST product (Reynolds and Marsico 1993). However, in situ measurements reported in Sengupta et al. (2001) and Webster et al. (2002) suggest that the oscillation of the SST during the evolution of a MISO may be at least a factor of 2 larger. It is thought that the underestimation is caused by a cloud bias in the Reynold's SST product. Other products are appearing such as the Tropical Rainfall Measuring Mission (TRMM) Microwave Imager (TMI) that do a far better job of estimating SST in the presence of clouds. However, as yet the dataset is not sufficiently long to build a meaningful training period.

Figure 5a shows a composite of the central India GPI precipi-

Fig. 5. (a) Composite of the central India precipitation plotted \pm seven pentads relative to maximum GPI precipitation occurring in the central India region in the 20-70-day band. The compositing strategy is different than that used to construct Fig. 4. However, Lawrence and Webster (2002) noted that in the intraseasonal band, the structure of the composites was largely independent of the point within the Indian Ocean basin chosen as the basis of a composite analysis. (b) The 10 predictors used in the analysis. The regions over which they were calculated are detailed in Table 2 together with a list of data sources. The heavy black line shows the time evolution of the mean predictor. The shaded blue area displays the variance of the predictors within \pm I std dev. Overall the predictors show a robust behavior that is consistent with the lifecycle of the MISO. b) (1) Arabian Sea $10 \mathrm{~m}$ U-wind

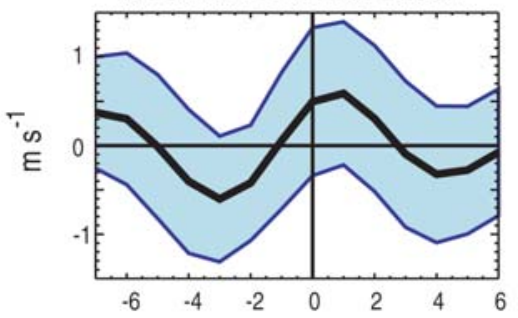

(2) Central Indian OLR

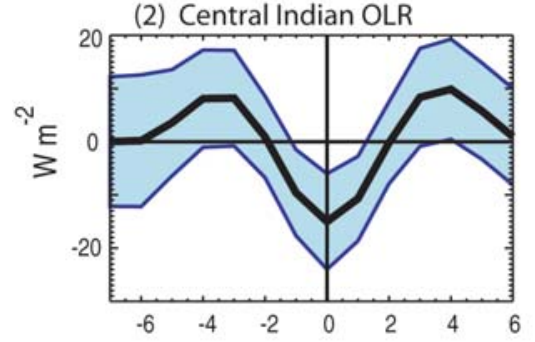

(3) Central India Soil Moisture

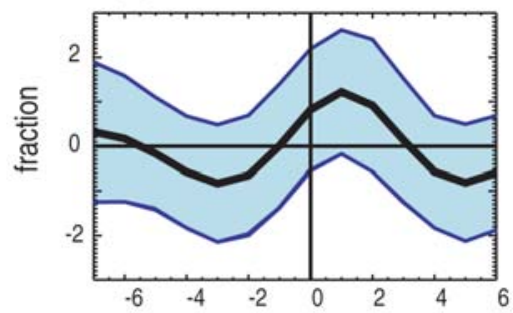

(4) Equ. Ind. Oce. $200 \mathrm{mb} U$-wind

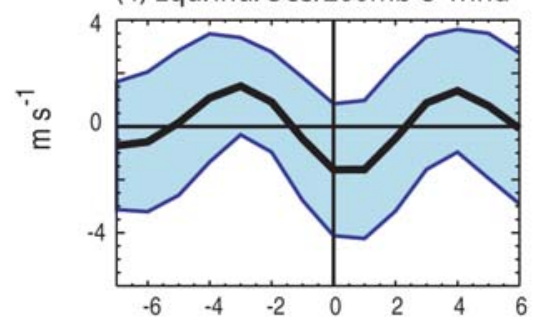

(5) Somalia Jet V-wind

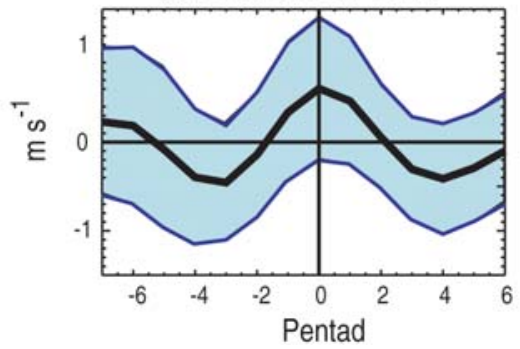

a)

Predictand: Central India GPI Precipitation

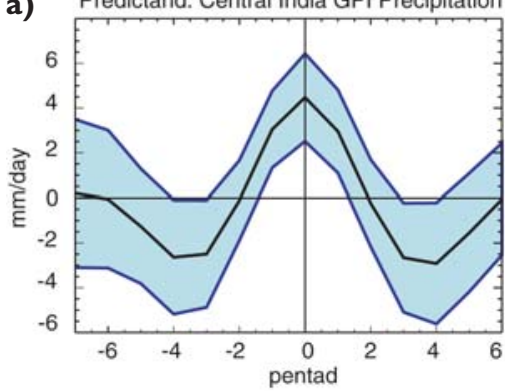

(6) Arabian Sea 10m V-wind

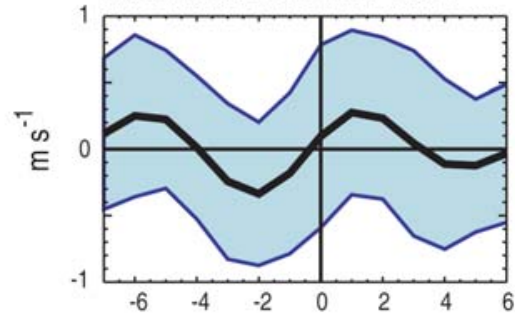

(7) Central India SLP

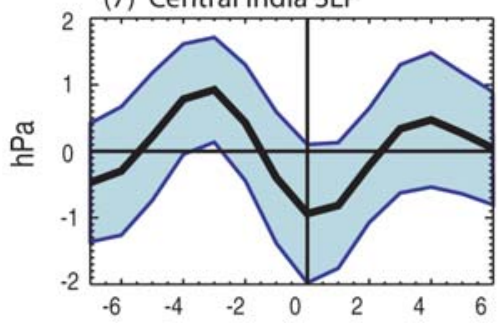

(8) Equ. Ind. Oce. $10 \mathrm{~m} \mathrm{U}$-wind

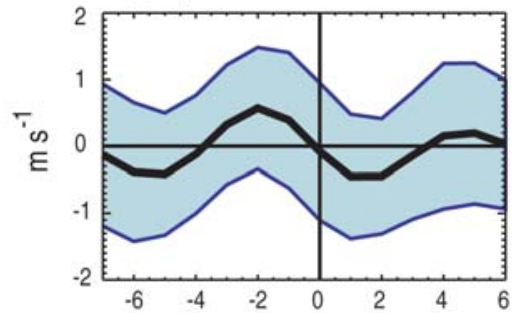

(9) Equ. Ind. Oce. OLR

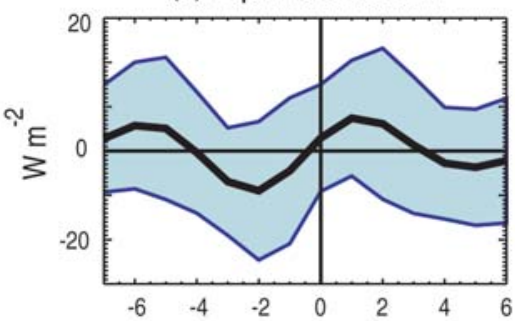

(10) Tropical E-Jet Index

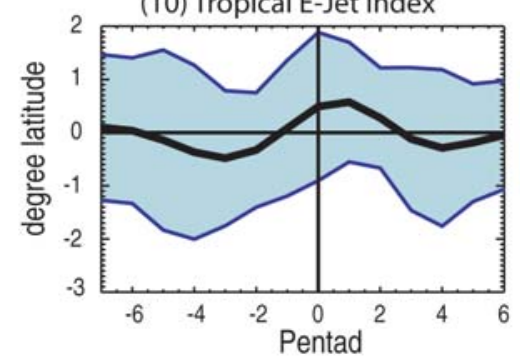


tation in the 20-70-day band. Similar composites are made for each of the predictors (Fig. 5b). The solid black line shows the mean composite behavior, and the blue lines and shading show the \pm one standard deviation about the mean. Day 0 is defined as the occurrence of maximum precipitation in the 20-70-day band. All quantities are shown for seven pentads before and after day 0 . Both the predictand and the predictor set show a tight structure before and after day 0 , with robust behavior during the life cycle of the composite MISO.

Figure $5 \mathrm{~b}$ shows the necessary behavior required of all predictors for substantial precipitation to occur over central India as depicted in Fig. 5a. The behavior depends not only on the magnitude of a predictor at a particular time but also on the tendency of the predictor. For example, three lags prior to the rainfall maximum the OLR over the equatorial Indian Ocean (predictor 9) must be negative (indicating substantial convection at the equator). But, in addition, the convection has to be weakening so that the OLR has a positive tendency. At the same time, the surface pressure over central India (predictor 7) must be decreasing, and so on. In this manner, the predictors set up a list of conditionals for precipitation to occur over central India. If, for example, the OLR over the equatorial Indian Ocean were to continue to become more negative then this would not lead to a precipitation maximum over central India, suggesting that northward propagation of convection is not occurring. In the above example we choose only two predictors (7 and 9). In reality we have 10 predictors, each having its own conditional behavior for the precipitation event to occur. The problem then reduces to building a statistical prediction scheme that takes into account the conditional behavior of the entire set of predictors.

Statistical scheme. Having chosen the predictand and the sets of predictors, we have a choice of a number of statistical tools that will produce a forecast. We choose a linear regression scheme to relate the predictand and the predictors. The predictors are chosen as described above. However, before the linear regression process is executed, we employ a "wavelet banding" (WB) technique to the predictand and to the predictors to sort the time series into specific spectral bands. This technique is described below.

In common with the other statistical schemes discussed later, the WB method is "blind" in that only past data are used in the forecasts described in subsequent paragraphs. That is, for a forecast starting at some time $t=t_{1}$ for a future time $t=t_{2}$, only predictand and predictor data collected prior to $t=t$ is used. Thus, each future point is independently forecast with a regression model constructed for each period to be predicted. For example, GPI precipitation data are available from 1986 to the present date. A 20-day forecast of central India precipitation from 1 May 2002, will use data from 1986 until 1 May 2002. For the next forecast initialized on 5 May 2002, data up to 5 May 2002 will be incorporated.

WAVELET BANDING. In general, geophysical time series are the result of nonlinear interactions between several physical processes occurring within a broad set of temporal and spatial scales. This means that time series are often made up of combinations of various frequency regimes with contributions present throughout the entire temporal domain or localized in time. The impact of these irregular transients makes forecasting of low-frequency events difficult. Consider a predictor such as the central India GPI precipitation (Fig. 6a). The WB method uses time series Morlet wavelet analysis (e.g., Torrence and Compo 1998) of the predictand up until the time of the forecast. Figure $6 \mathrm{~b}$ shows the wavelet spectra of the pentad GPI precipitation product averaged over the central India region (see Fig. 1) for the entire data period. From the average wavelet spectra (Fig. $6 \mathrm{c}$ ) the frequency bands of strongest and statistically significant variance are isolated. Four significant spectral regions are found: $5-20,20-75,75-230$, and $>230$ days. For each forecast, the wavelet is recomputed. Using the frequency bands defined in the wavelet analysis of the predictand, the predictors are analyzed identically. That is, for each of the four frequency bands there is 1 predictand and 10 predictor time series. So, in total, there are 4 predictands and 40 predictors. These time series are spectrally separated using inverse wavelet filtering (e.g., Fig. 6d), which works in the same sense as Fourier filtering (e.g., Torrence and Compo 1998).

THE REGRESSION SCHEME. A simplified version of the general scheme is shown in Fig. 7 for one band and just three predictors. Four future values are to be predicted. As each value represents a pentad, this implies a 20-day forecast in steps of 5 days. Figure 7 a shows all of the knowledge of the state of the system that is available at the time of the forecast. To forecast the first step (i.e., pentad 1 or day 5 , marked as the heavy arrow), we lag the predictor variables one position with respect to the predictand variable (Fig. 7b). The shaded box contains all of the information that will be used. Note that if the original dataset has $n$ points, 
the fitting to forecast the first point will be performed using $(n-l)(p-l)$ multiples, where $p$ is the number of predictors. That is, if $y$ were the predictand, the values used to perform the fitting would be $y(2)$ to $y(n)$, and if $X$ were the predictor set, the values used would be from $X(1)$ to $X(n-1)$. If the regression equation is $R[X(t)]$, the predicted value would be calculated as $y(n+1)=R[X(n)]$. Figure 7c shows the same procedure for the prediction of the second value $y(n+2)$. In this case, the predictors are lagged two positions and the data used to fit the predictand are from $y(3)$ to $y(n)$ and $X(1)$ to $X(n-2)$. Figures $7 \mathrm{~d}$ and $7 \mathrm{e}$ show the same procedures for the $y(n+3)$ and $y(n+4)$, respectively. In general, to forecast the $m$ th future value of $y$ [i.e., $y(n+m)$, where $m<<n]$, the regression equations are constructed using $n-m(p+1)$-tuples from $y(1+m)$ to $y(n)$ and $X(n-m)$.

Having set up the system, we require a regression technique. We choose the simplest-a multilinear regression scheme (LIN) so there will be four sets of regression equations, one for each band identified in the wavelet analysis. To obtain the final forecasted value, the predictions in all bands are added together. The isolation of bands in a time series by wavelet analysis is the key factor in the WB statistical scheme (see appendix) because it allows the regression tool to identify, independently in each band, the existing relationship between the predictand and predictors. That is, the "noise" from other spectral bands is not allowed to affect the construction of the regression equation. The isolation of one band from the noise in another was the basis of the numerical scheme proposed by Krishnamurti et al. (a) Central India GPI Precipitation

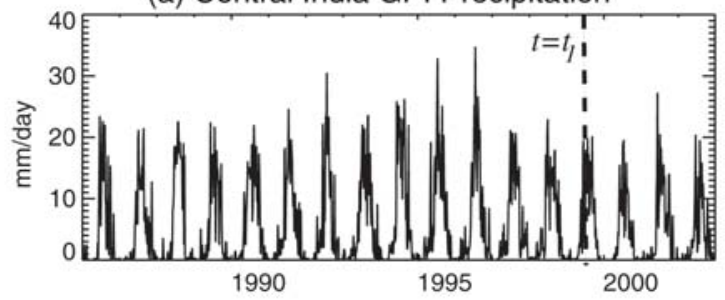

b) Wavelet Analaysis of Ganges Precipitation

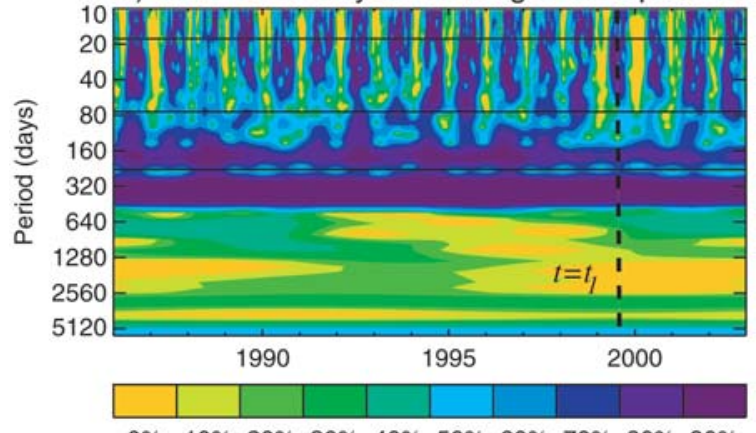

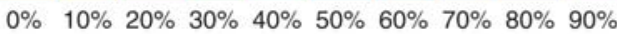

(d) Time Series of Wavelet bands
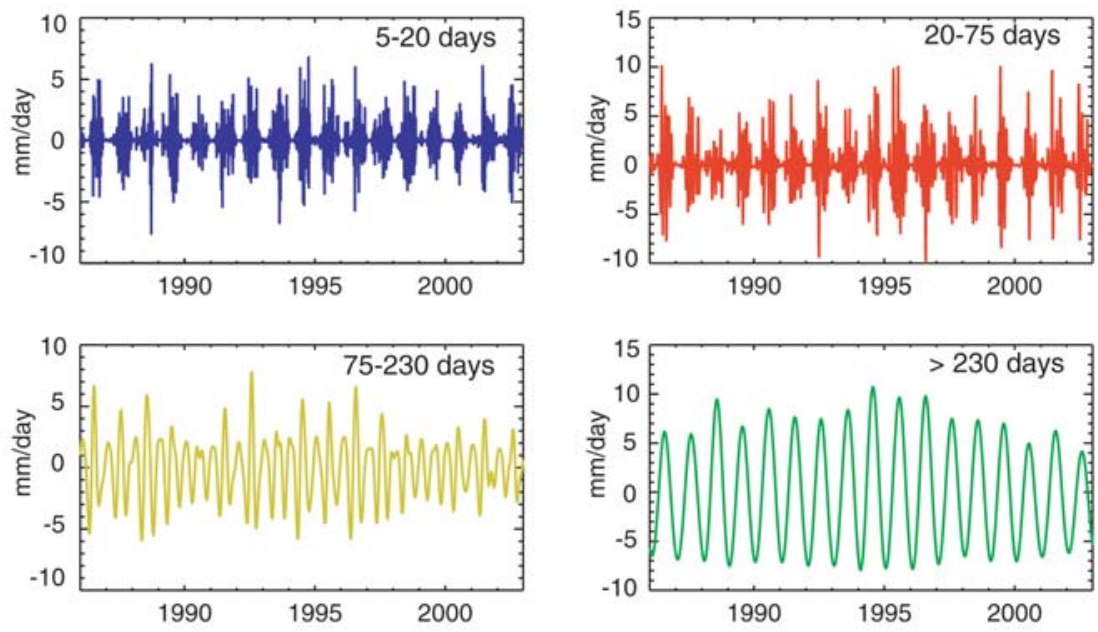

FIG. 6. Description of the WB technique: (a) time series of a predictor, in this case the GPI rainfall estimate over central India from 1986 through 2002; (b) wavelet analysis of the predictand for the same period; (c) the average wavelet spectra over the period 1986-2002. The wavelet bands are chosen from regions within the average spectra that are statistically significant. These bands are 5-20, 20-75, 80-230, and $>230$ days. (d) Time series of the four wavelet bands. For a forecast initiated at $t=t$, [vertical line in (b)], wavelet analysis and the identification of the wavelet bands would be undertaken on data collected at $t<t_{l}$. Note that the resultant bands (d) possess amplitudes with varying coefficients. All of the predictors (Table 2) are banded identically. The wavelet banding and the careful choice of predictors are the fundamental basics of the statistical scheme. 
(a)

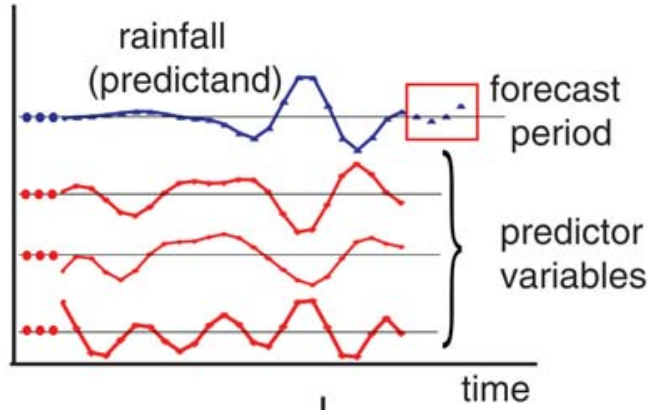

(b)

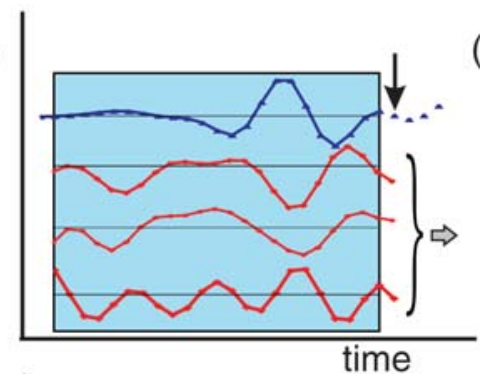

(c)

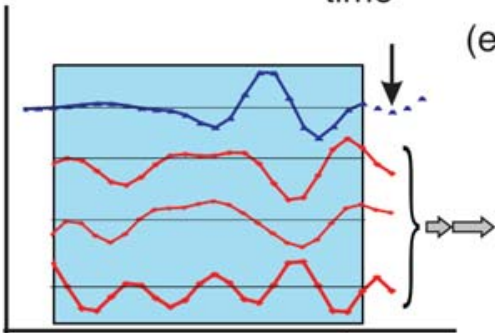

time (d)

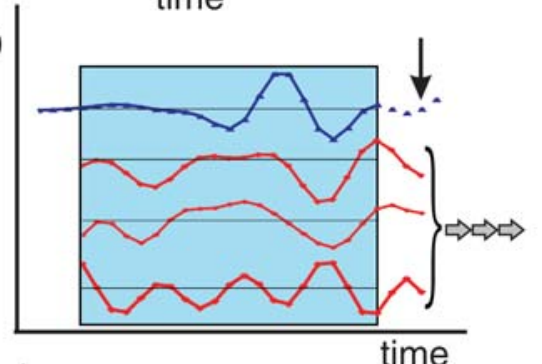

(e)

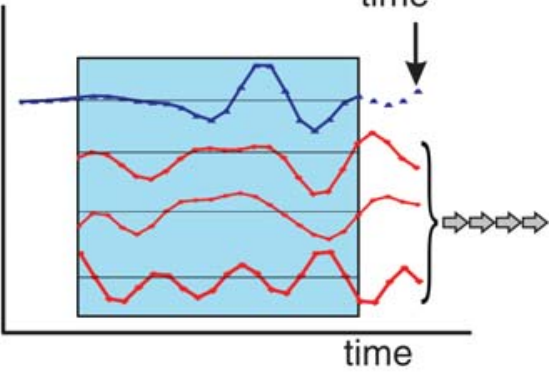

Fig. 7. Example forecast algorithm for four future values (20 days) of the predictand. (a) Blue curve represents one band of the predictand (e.g., the 20-80-day band of central India rainfall) up to time $t=t$. Red curves show predictor set (here simplified to three) from the same wavelet band as the predictor. Three other predictand-predictor sets exist to represent the other wavelet bands (not shown). (b) The forecast of the first value (downward arrow) comes from lagging the predictors one step in time (horizontal arrow). Blue boxes contain all the information that will be used to construct the predictand equations. (c)-(e) Forecasts of successive values of the predictand. Here we use a linear regression scheme to advance each of the wavelet bands. At the end of the process, the bands are recombined to provide the total forecast values of the predictand.

(1990), which we discuss briefly in the section on "Conclusions and future work." The implementation of the regression scheme results in the production of sets of multilinear time series with time-dependent coefficients. In this manner, the coefficients of the regression equations vary over time as different predictors change in their relative importance. In fact, this property can be gleaned from correlograms of the predictands and the predictors (not shown) that indicate that different variables assume ascendancy in various frequency ranges.

PREDICTIONS. Forecasts of central India precipitation. Figure 8 shows 20-day (four pentads) forecasts

for the central India region. Forecasts for the summers of 1999-2002 are displayed. The gray line represents the GPI observation record, and the blue lines show the forecast values made 20 days prior using the $\mathrm{WB}$ technique, with linear regression summed over the four spectral bands using information only available at the time of the forecast. Overall, the 20-day forecasts manage to discern the phase of the major variations of the pentad GPI rainfall quite well. Most peaks and valleys align fairly accurately with observations. Whereas the amplitude of the forecasts is generally underestimated, it is rare that extrema in forecasts and evaluation fields are missed. Based on hindcasts for the period 1992-2003, the anomaly correlations for $10,15,20$, 25 , and 30 days for the central India rainfall predictions are $0.88,0.76,0.73$, 0.66 , and 0.58 , respectively.

In addition to forecasting intraseasonal variability of the monsoon, the scheme also appears to determine the commencement of the monsoon rains over central India with some accuracy. These determinations include a number of "false onsets," as identified by Flatau et al. (2001). As this MISO-specific statistical system picks up the commencement of rain, it seems that there is some support for the hypothesis that the onset of the monsoon is the first MISO of the summer season (Webster et al. 1998; Flatau et al. 2001).

Forecasts of Brahmaputra and Ganges River discharge. The Brahmaputra and Ganges River basins (Fig. 1) have drainage areas of 589 and $107310^{3} \mathrm{~km}^{2}$ and average discharges of 630 and $490 \mathrm{~km}^{3} \mathrm{yr}^{-1}$, respectively. The rivers rank as the 6th and 11th largest on the planet in terms of discharge into the ocean. The com- 
mon feature of the two river systems is that they both pass through Bangladesh into the top of the Bay of Bengal. In so doing, they create annual flooding, causing various degrees of disruption to life, agriculture, and commerce in Bangladesh. Because of the unavailability of discharge data, only discharge measured at the borders of the country is used for flood forecasting in Bangladesh. Consequently, flood forecasts with only 2-day lead times are currently possible in Bangladesh. The period is determined by the average flow-through time between the borders and the Bay of Bengal. A time series of the discharge of the two rivers is shown in Fig. 9a.

A strong relationship exists between the discharge of the two rivers into Bangladesh and the rainfall in the catchment regions. It is a nonlinear relationship that takes into account land-use practices, evapotranspiration, water retention, etc. To forecast river discharge, we use the two time series of Brahmaputra and Ganges River discharge (Fig. 9a) as predictands. Given the strong relationship between integrated rainfall and discharge, we use the same predictors shown in Table 2. Figure 9b shows the observed (black curves) and the 20-day forecasts (red and blue curves) of the Brahmaputra and Ganges for the years 1998 and 1999. The statistical scheme, trained on discharge data from 1986 until the time of the initiation of a forecast, shows useful skill in forecasting discharge into Bangladesh from both rivers.

Scale-dependence of precipitation forecasts. Large gradients in total seasonal precipitation occur from the eastern to the western parts of central and northern India: $2000 \mathrm{~mm}$ in Orissa to $450 \mathrm{~mm}$ in Rajasthan (see Fig. 1). The areas of the two states are roughly $30 \%$ and $15 \%$ of the central India region, respectively. The question is whether or not the statistical scheme works with sufficient skill to be useful on areas the size of these Indian states.

Figure 10 shows 20-day GPI precipitation forecasts for the states of Orissa and
Rajasthan. The overall mean rainfall is reproduced quite well, including much of the intraseasonal variability. However, it should be noted that the overall skill is less than that found for central India for any of the four years. Twenty-day forecasts using the WB method explained about $79 \%$ of the variance of central India precipitation and $74 \%$ and $75 \%$ of the variance for Rajasthan and Orissa, based on $10 \mathrm{yr}$ of hindcasts. Once again there is an underestimation of the amplitude of the peaks, and also occasionally a peak may be missing such as during the summer of 2000 in Rajasthan during late July and early August.

\section{COMPARISON OF SKILL WITH OTHER} STATISTICAL TECHNIQUES. We compare briefly measures of skill of the WB scheme with the skill from other models. In particular, we choose the LIN model, used earlier as a component of WB, a multivariate adaptive regression spline model (MARS) (Friedman 1991), and an artificial neural network (ANN) model. [Algorithm JETNET from Lund University, Sweden, is used (downloadable online at www-dapnia.cea.fr/Spp/Experiences/OPAL/ opalcern/nnbegin.html; documentation online at www.thep.lu.se/public_html/jetnet_30_manual/ jetnet_30_manual.html).]. A time section of the fore-

\section{0-day precipitation forecasts central India}
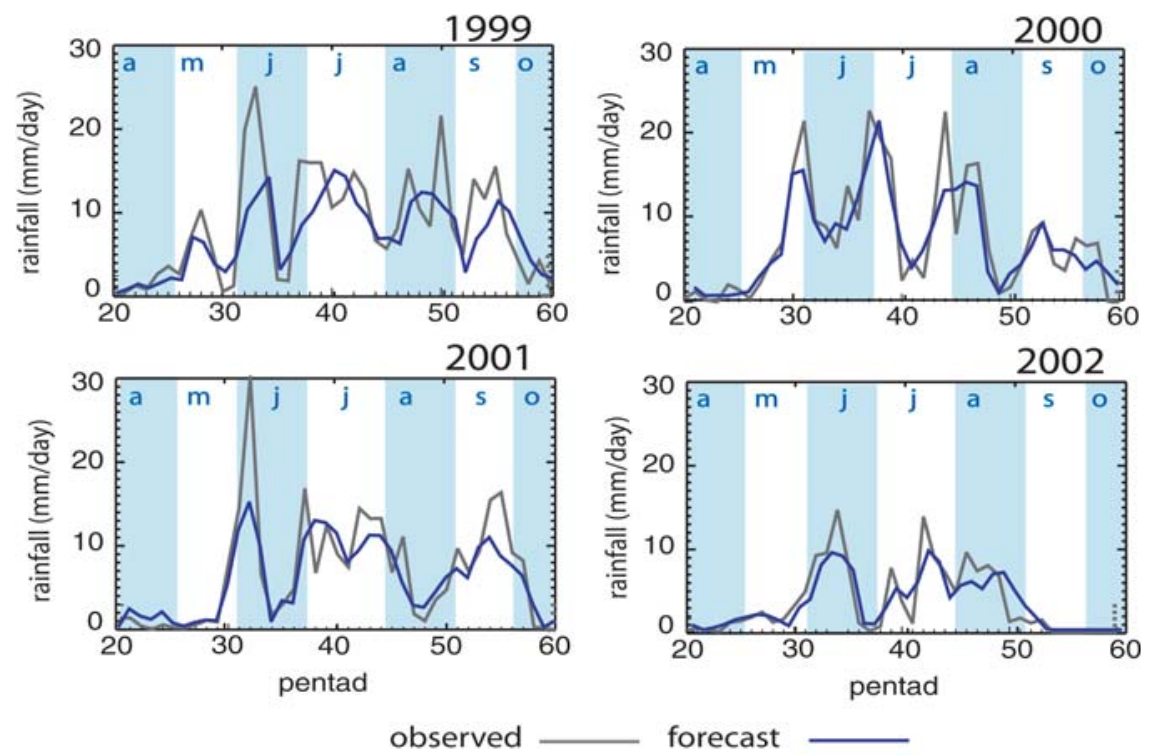

FIG. 8. The 20-day forecasts of precipitation averaged over central India, defined in Fig. I, for the summers of 1999-2000. Blue lines indicate 20-day (four pentads) forecasts, while the dark gray lines indicate observational validations using area averages of the GPI precipitation. The WB forecast scheme manages to forecast the phase of the rainfall variability with significant skill, although the amplitude of high-frequency peaks is underestimated by the scheme. Blue and white background denotes months. 
casts for each of the schemes is shown in Fig. 11a for the summer of 2002, relative to the observed precipitation (dark gray). All schemes forecast the low-frequency envelope of the annual cycle. Both the MARS and ANN models appear to show some resemblance of intraseasonal variability, especially the first rainy

(a) Observed Ganges and Brahmaputra Discharge into Bangladesh

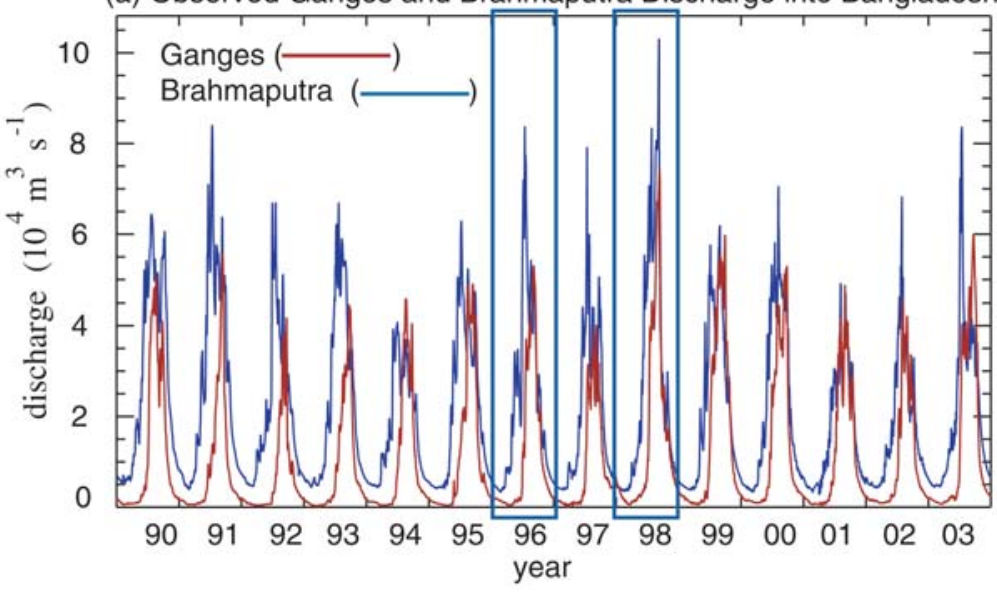

cycle. Both show a decrease of precipitation during late June and early July but do not forecast a cessation of rainfall. The skill of these forecasts decreases substantially later in the season. Forecasts using the linear regression model show no evidence of intraseasonal variability.

Figure $11 \mathrm{~b}$ compares the model forecasts using a number of statistical tools. The root-mean-square error (rmse) and forecast skill (skill) is defined as

rmse $=\sqrt{\frac{\sum_{n}[\chi(i)-\bar{\chi}(i)]^{2}}{n}}$

and

skill $=\left(1-\frac{\operatorname{rmse}(\chi)_{\text {prediction }}}{\operatorname{rmse}(\chi)_{\text {observation }}}\right) \times 100$, (b) 20-day forecast of river discharge into Bangladesh
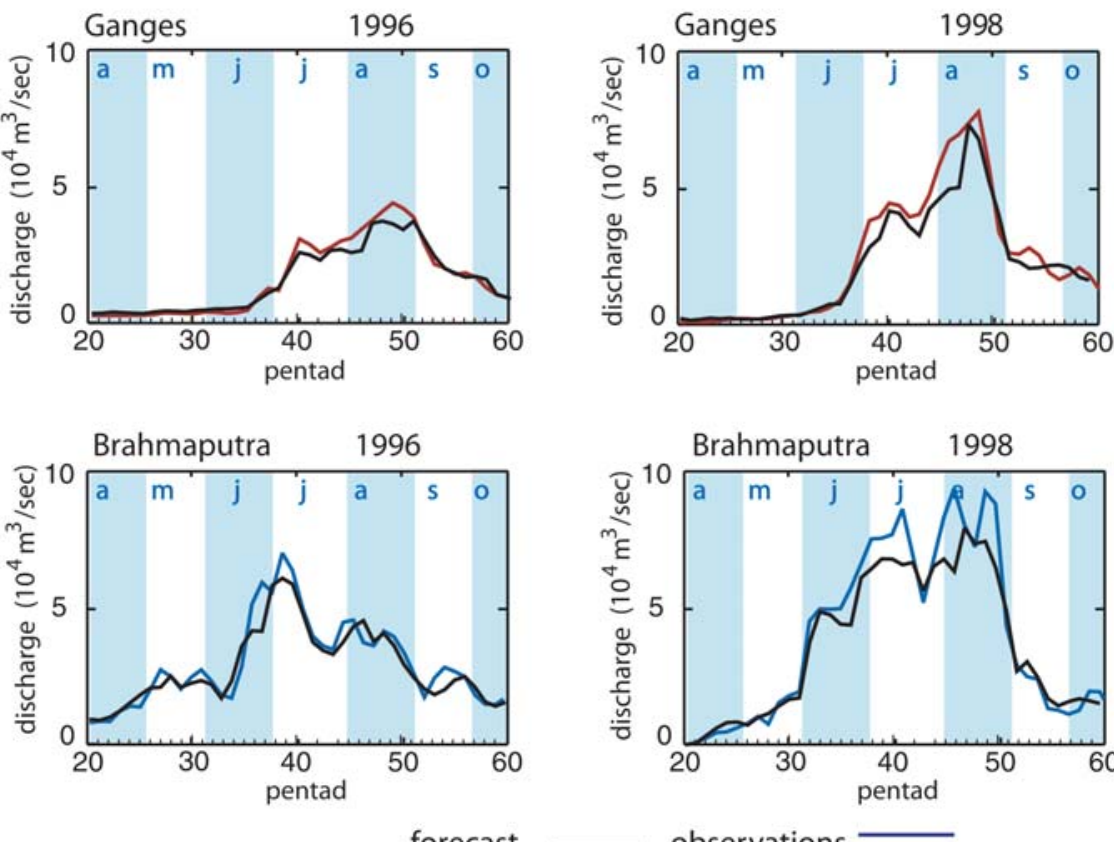

forecast

observations

FIG. 9. (a) River discharge $\left(10^{4} \mathrm{~m}^{3} \mathrm{~s}^{-1}\right)$ of the Ganges (red) and the Brahmaputra (blue) Rivers at their entry points into Bangladesh (as shown in Fig. Ib) for the years 1990 through 2003. The time series show a great difference in the characteristics of the discharge of the two rivers, but both show interannual and intraseasonal variability. Two years are highlighted: 1996 and 1998. During the latter year, floodwaters covered over $60 \%$ of Bangladesh for a 3-month period. (b) The 20-day forecasts of discharge into Bangladesh by the Bayesian WB scheme for the years 1996 and 1998. Black lines show the 20-day forecasts, while the blue and red lines show the observed discharge of the Brahmaputra and Ganges, respectively. where $\chi$ may be the predictand $y(n)$ or the tendency of the predictand $[y(n)-y(n-1)]$. On all lags, the WB forecast outscores other methods. For example, correlations between forecasts and observations are $>0.8$ for WB but $<0.6$ for the other schemes. Most of the correlation skill in the MARS, ANN, and linear schemes come from the forecasting of the annual cycle envelope. Also, the root-mean-square error is far smaller for WB than for the other schemes. When tests are applied to tendencies of the predictands rather than absolute values, WB still outperforms the other schemes.

\section{CONCLUSIONS AND} FUTURE WORK. The time scale of a forecast for optimal application in the agriculture and water resource sectors of monsoon 
regions is about 15-25 days (Subbiah 2004). We have argued further that forecasts at longer time scales (e.g., the mean summer rainfall over the entirety of India) have a smaller practical value than forecasts of the intraseasonal variability because of downscaling problems. We have shown that a relatively straightforward statistical scheme based on the physical components of the intraseasonal oscillations is able to make forecasts with considerable skill on time scales that are useful for applications. Whereas a careful choice of the predictors is a necessary condition, it is not sufficient to produce skillful forecasts. For example, three other schemes (MARS, ANN, and LIN) use the same predictors. Predictions from these three schemes show similar skill to other statistical efforts aimed at forecasting gross aspects of intraseasonal variability in the Tropics (e.g., von Storch and Xu 1990; Waliser et al. 1999; Mo 2001; Lo and Hendon 2000; Wheeler and Weickmann 2001), but all are less skillful than the WB method. Clearly, the discriminating feature of the method is the use of wavelet banding. An analysis in the appendix explains why skill is enhanced. Simply, the WB scheme works because of the careful choice of predictors and the separation of frequency bands, which does not permit noise in one band to influence signals in another band.

There are four major areas in which further work is required:

i) General utility of the scheme. It is tempting to speculate that the scheme with modified predictors will be applicable to any region where simi-
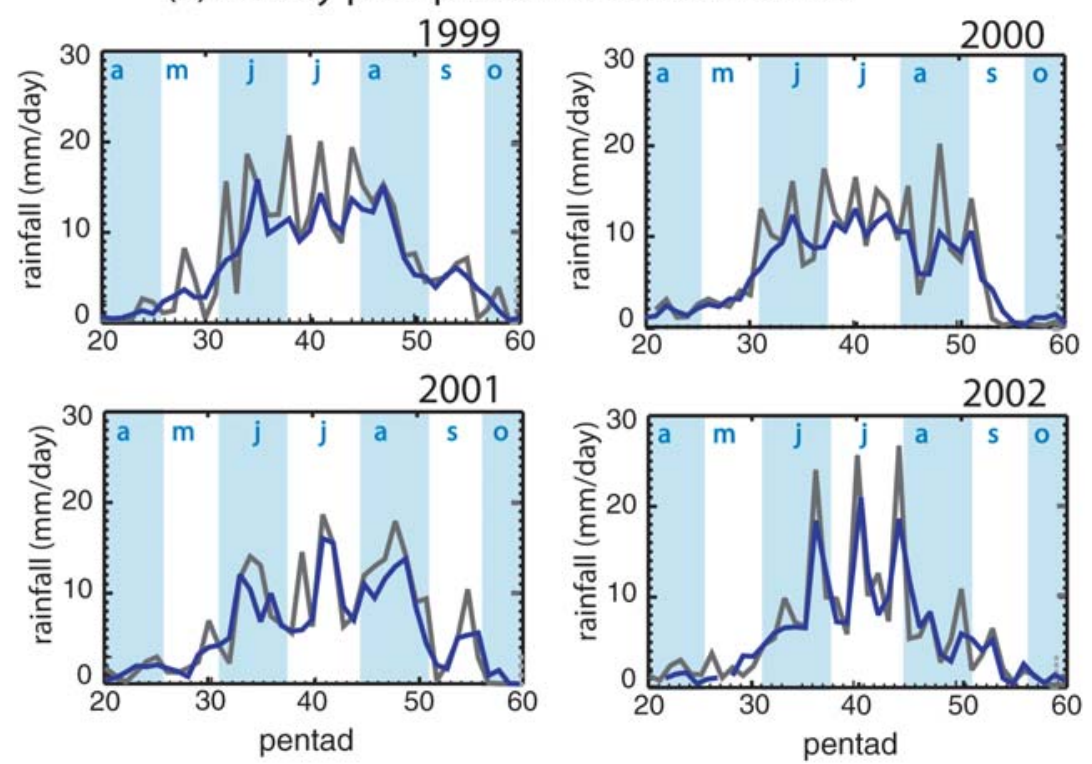

(b) 20-day precipitation forecasts Rajasthan
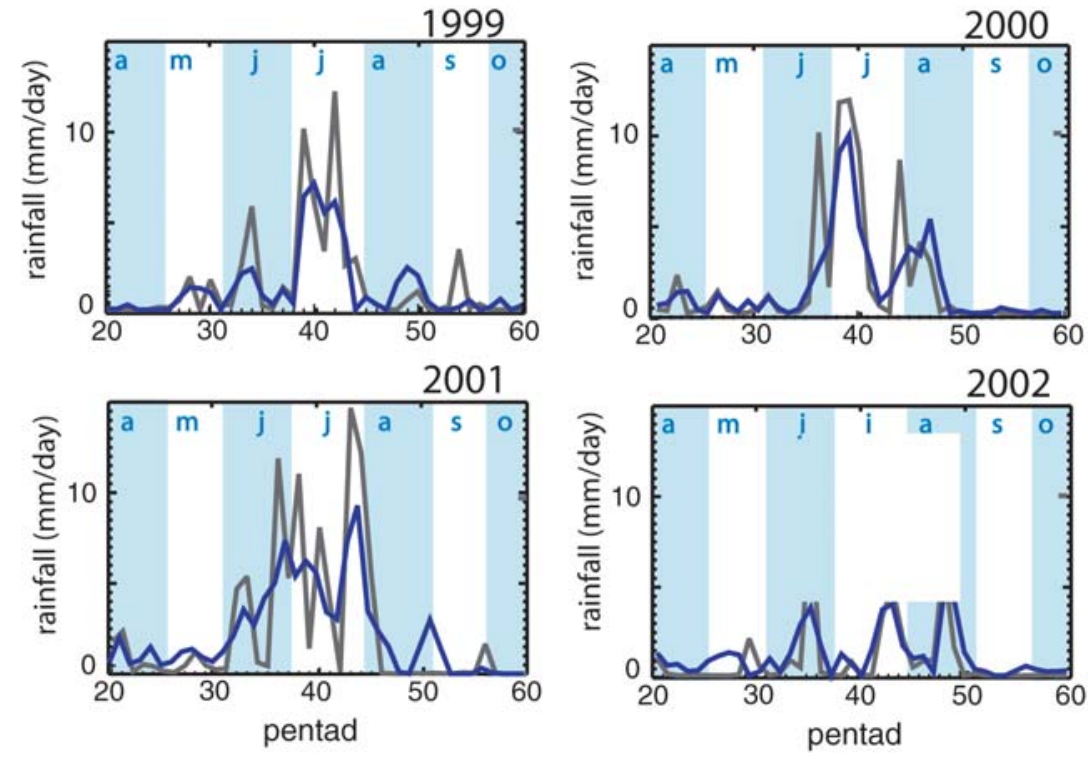

observed

forecast

Fig. 10. Same as Fig. 8 except for 20-day forecasts of precipitation for the Indian states of Orissa and Rajasthan (see Fig. I). Even though the area of each state is significantly smaller than the central India region, the WB scheme still manages to capture the major intraseasonal events some time in advance, albeit with reduced skill. lar intraseasonal oscillations of a monsoon climate take place (e.g., north Australia, east Asia, and Indonesia). We intend to test the scheme in these locations. As there needs to be a clear spectral differentiation to allow meaningful banding in the wavelet analysis, it is possible that the 
scheme may have limited application. We will examine the low-frequency phenomena in Africa and the Americas to see if they are also candidates for the WB scheme.

ii) Probabilities. A strength of Bayesian statistics is that probabilities of occurrence can be calculated for a particular forecast. For applications, the probability of an event occurring is an essential component of a forecast because it allows a costloss analysis to be made. For example, consider the first maximum in precipitation forecast in 2002 for the central India region (Fig. 8). At pentad 31 a maximum in precipitation was forecast at pentad 35. The forecast was for a precipitation rate averaged through the pentad of $9 \mathrm{~mm} \mathrm{day}^{-1}$. The observed value turned out to be $14 \mathrm{~mm}_{\text {day }}{ }^{-1}$. A more useful forecast would have been to provide a range of probabilities of rainfall rate. Essentially, the forecast scheme used in this study weighs the evolution of the 10 predictors relative to the past behavior of the predictors. That is, a forecast is made relative to the joint probabilities of a series of events occurring through the forecast period. Such occurrences are measured relative to their statistical priors, which can be turned into probabilities.

An immediate extension of the WB method that we propose is to take full advantage of the Bayesian structure of the model and develop probability density functions for each forecast. Figure $5 \mathrm{~b}$, which shows the composite behavior of the predictors and their variance, points toward how probabilities estimates are natural extensions of the WB scheme. The composites were constructed from 53 MISOs occurring since 1986. Thus, at any time during the monsoon season, there is a value occupied by each of the predictors. Based on their values and their tendencies, it will be possible to calculate probability distributions. A second method being explored uses the history of hindcasts to document residuals between the forecast and the validation field. This procedure establishes a history of uncertainty in the forecast. By examining the current residual patterns, "nearest neighbor" residuals can be determined from the archive. All forecasts will have a family of nearest neighbor sets from which a forecast probability distribution function of the predicted state can be determined.

iii) Use of the WB scheme as a diagnostic tool. Since the forecast scheme is physically based, skill comes from the interplay and sequencing of physical processes that have occurred during the training periods. From Figs. 7-9, it is clear that the model is capable of recognizing a series of conditional processes that allow the monsoon rainfall to occur at a particular time, for the overall monsoon rains to be above or below normal (e.g., Fig. 8) and capture the phasing of the intraseasonal events. It may be possible to construct the inverse problem and determine the reasons for the occurrence (or nonoccurrence)

(a) Comparision of statistical schemes for rainfall prediction
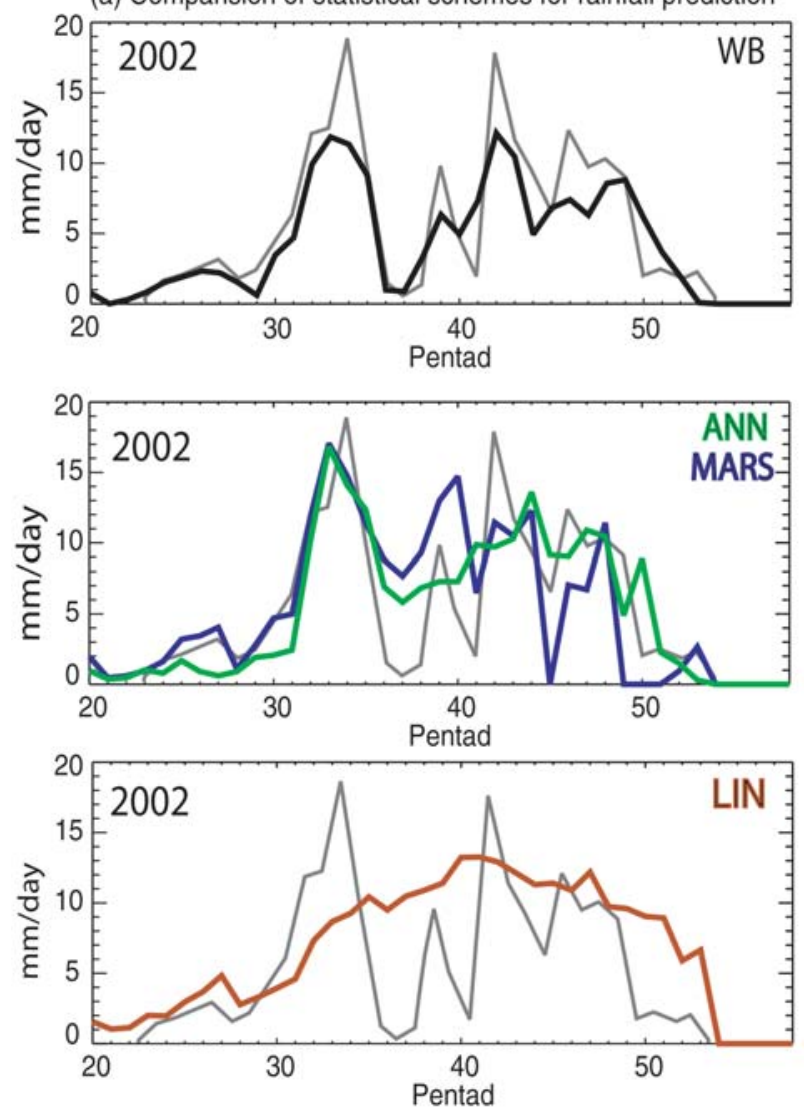

FIG. II. (a) Comparison of three other Bayesian schemes (ANN, MARS, and LIN) with the WB scheme for a 20-day prediction for the Ganges Valley GPI precipitation estimate. The observed precipitation rate is shown as the dark gray curve in each panel. The same physically based predictors were used in each scheme. The ANN and MARS schemes appear to anticipate the first active period quite well, although both miss the midseason break. The LIN model shows little correspondence to observations except for giving a fair reproduction of the annual cycle. (b) (facing page) Comparison of the statistics of the four Bayesian schemes for $10 \mathrm{yr}$ of hindcasts for GPI precipitation over the Ganges valley. In all six measures of performance the WB scheme scores best. In addition, the anomaly correlation coefficient is shown as the black dashed line in (i). The statistical measures are defined in the text. 
of an event. For example, is it possible to determine what physical processes created the "false" onset in 1999 (Fig. 8) versus the full onset of the monsoon rains noted in 2000 (Fig. 8)? Can examination of the predictors and their sequencing determine why the model produced forecasts of less total rainfall in 2002 over central India than in the other four years shown in Fig. 8? Finally, is it possible to use the inverse model to help increase the skill in numerical models perhaps by examining the statistical predictors in comparison to the same physical processes produced by the numerical models as they evolve through time during a particular MISO? (i) correlation time series

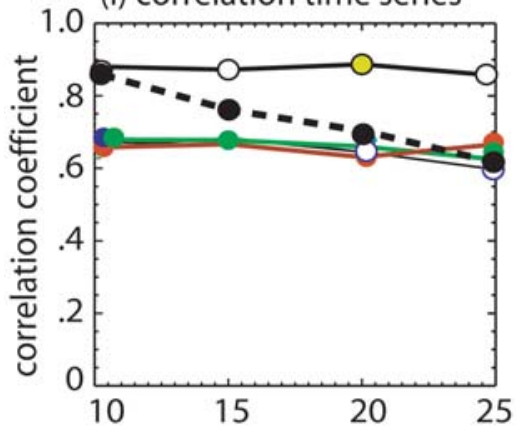

(iii) root mean square error

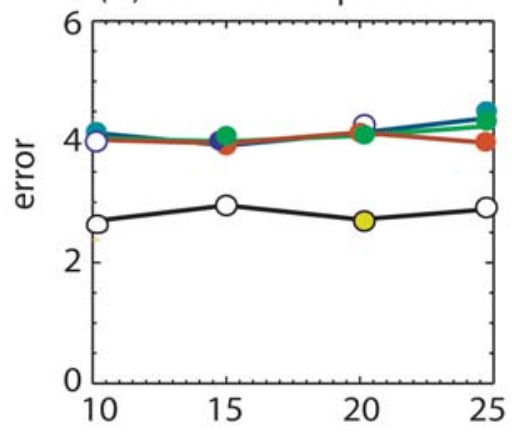

(v) forecast skill

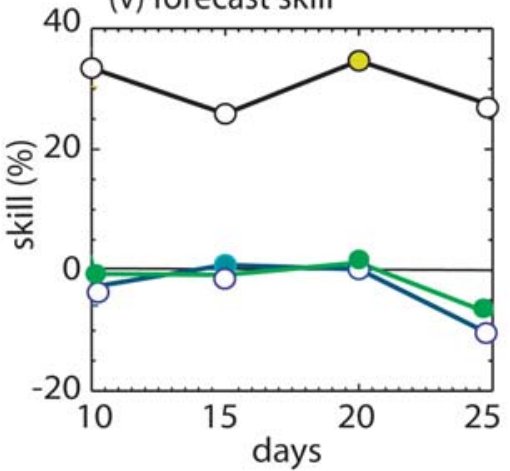

\section{(ii) correlation of tendencies}

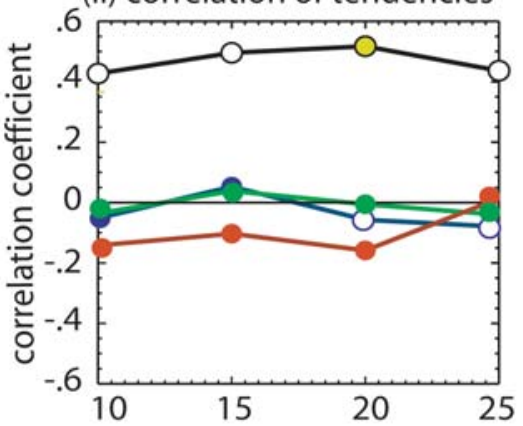

(iv) rmse of tendencies

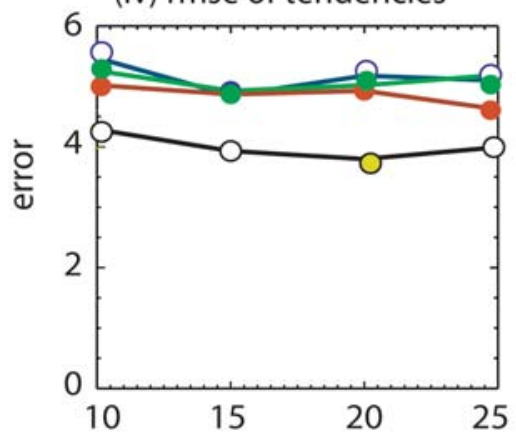

(vi) forecast skill (tendency)

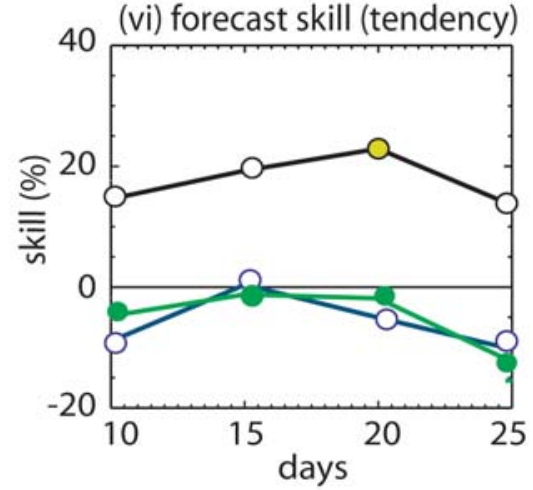

ANN

MARS

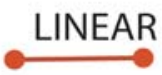

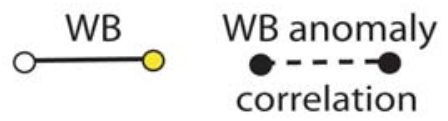

iv) Wavelet banding and numerical modeling. During recent years the tendency in numerica has been to increase spatial resolution forecasts. For example, Randall et al. (2003) estimate that there would be a thousandfold increase in computer time for the inclusion of twodimensional cloud-resolving schemes and even higher-order increases for three-dimensional schemes. Whereas at some time in the future these efforts may be successful, it is prudent to ask if there are ways of going toward simpler modeling rather than following the higher-resolution explicit physics route. For example, can the WB method suggest an alternative path, especially for modeling intraseasonal variability?

In a series of innovative papers, Krishnamurti et al. (1990, 1992, 1995) attempted to predict intraseasonal variability numerically. Noting that "A major limitation of the extended integrations arise from a contamination of low frequency modes as a result of energy exchanges from the higher frequency modes" (Krishnamurti et al. 1990), the studies filtered out from the initial data all but a mean state and a low-frequency band of 30-50 days. They found improvements in skill out to about 20 days before the forecast deteriorated, at which time higher-frequency modes, generated within the forecast, contaminated the low-frequency system. To some extent, the Krishnamurti et al. papers were replicating a numerical version of the WB method, but with one exception. In the WB method, 
the bands are kept separate throughout the forecast. In the Krishnamurti et al. studies, high-frequency noise was allowed to be generated following initialization. Whereas there may be substantial technical barriers, we speculate that if the bands can remain separated after initialization many of the current problems in simulation and prediction of intraseasonal variability may be overcome.

ACKNOWLEDGMENTS. Funding for the basic research and the development of the prediction scheme was from a grant by the National Science Foundation's Climate Division under NSF Grant 0120956. Funding for applications of the forecast scheme in Bangladesh comes from a grant from USAID. The authors would like to thank Drs. R. Grossman, J. Curry, and K. Sahami, and Mr. T. Hopson and Mr. J. Jian for many informative discussions. We are especially grateful for the encouragement of the late Professor J. R. Holton who appreciated the need for theorists to do useful things. We are especially indebted to Sri. A. Subbiah of ADPC for his continual encouragement and for his advice on the needs of the farming communities of south Asia. We thank Dr. Krishna Kumar Kooli from IITM Pune, India, for providing the data used in Fig. 3a. Finally, we appreciate the extensive reviews of Dr. D. Waliser, Dr. J. Shukla, and the anonymous reviewer.

\section{APPENDIX: SIMPLE EXAMPLE OF WAVE-} LET BANDING. In general, geophysical time series are made up of many temporal scales with coefficients that vary in time. These factors make the task of prediction more difficult. Wavelet banding attempts to improve forecasting skill cast $F^{\prime \prime}(t)$. by making use of all available spectral information. Figure A1 is a simple example of why combining traditional fitting tools with spectral techniques is useful. For explanatory purposes, the example we choose is very simple and we assume that the coefficients of the functions are constant in time.

Consider a predictand $F(t)$ that is represented by two periodic modes given by

$$
F(t)=2 \sin (t)+\sin [6(t)],
$$
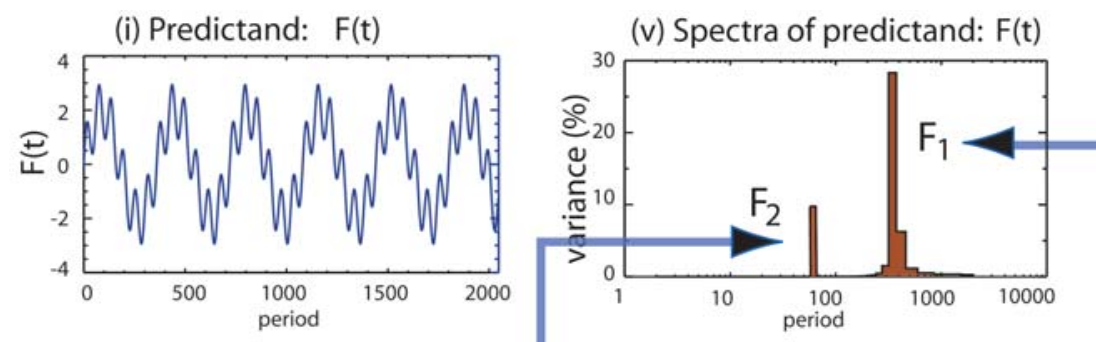

(ii) Predictor 1: $\mathrm{G}(\mathrm{t})$

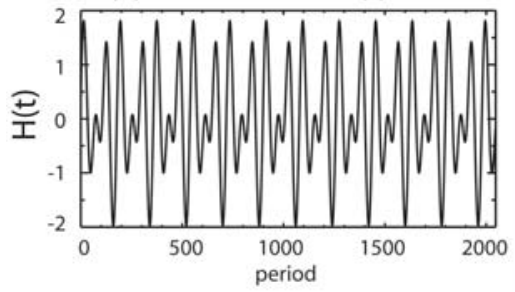

(vi) Spectra of predictor 1:G(t)

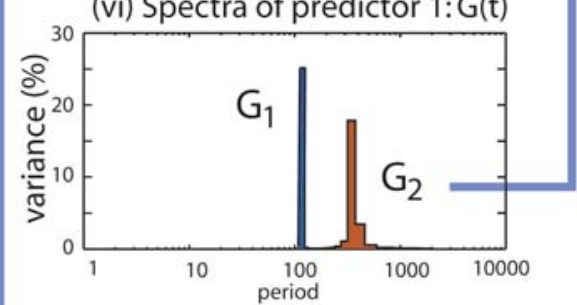

(vii) Spectra of predictor 2: $\mathrm{H}(\mathrm{t})$
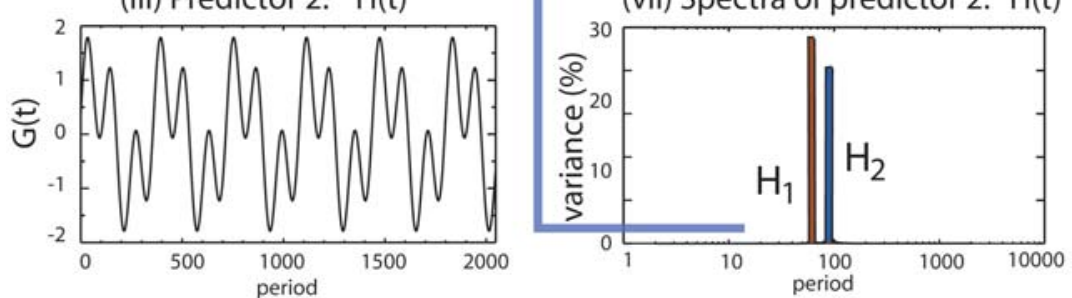

(iv) LIN fitting for lag=20: $F^{\prime}(t)$

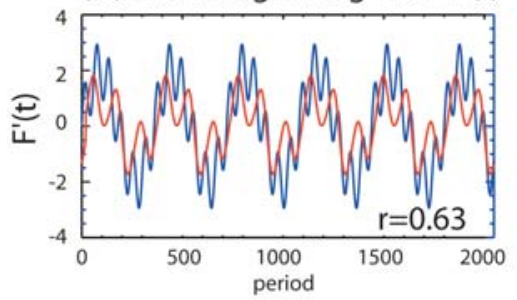

(viii) WB fitting for lag=20: $F^{\prime \prime}(t)$

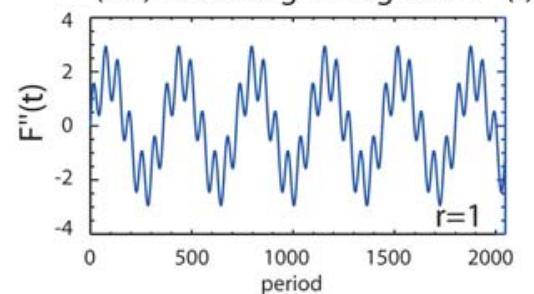

Fig. Al. Example of the WB method. (i) A simple periodic predictand $F(t)$ is chosen with two periodic predictors (ii) $G(t)$ and (iii) $H(t)$. Using a linear regression technique (e.g., LIN) to forecast 20 lags produces (iv) the function $F^{\prime}(t)$. The correlation between $F(t)$ and $F^{\prime}(t)$ is 0.63 . However, if the spectra of the (v) predictand is noted and a spectral (or wavelet) banding applied in which (vi), (vii) the predictors are also banded, only part of the predictor functions will be used to predict. Predictor components $T_{1}(t)$ and $H_{1}(t)$ are discarded and $G_{2}(t)$ is used to predict component $F_{2}(t)$ and $H_{1}(t)$ component $F_{2}(t)$ (large blue arrows). The result for this simple case is (viii) a perfect fore- 
as shown in Fig. Ala. Assume that there are two predictors $G(t)$ and $H(t)$ that are also periodic and stationary:

$$
G(t)=\sin (t+20)+\sin (3 t)
$$

and

$$
H(t)=\sin (6 t+20)+\sin (4 t) .
$$

The functional form of the predictors is shown in Figs. $11 \mathrm{~b}$ and $11 \mathrm{c}$. Let us assume that we intend to do a 20-step forecast of $F(t)$ using the predictors $G(t)$ and $H(t)$. There are two methods we can employ. We can use the LIN or WB methods:

i) LIN: We use the linear regression system, described in the text, to find a fitting expression and then compute the future values of the predictand $F(t)$. The predictand after 20 days lagging $\left[F^{\prime}(t)\right]$ is shown in Fig. 11b. The red curve shows 20-day forecasts of $F(t)$. The correlation coefficient between $F(t)$ and $F^{\prime}(t)$ is 0.63 .

ii) WB: If, instead of using the raw time series of the predictors, the prediction can be improved using the wavelet-banding method. Note that in this simple case, the amplitude distribution of the wavelet at any time is the same as the average wavelet spectra. We divide $F(t)$ into two bands:

$$
F_{1}(t)=2 \sin (t) \quad \text { and } \quad F_{2}(t)=\sin (6 t) .
$$

The predictors are also divided spectrally so that $G_{1}(t)$ $=\sin (3 t), G_{2}(t)=\sin (t+20)$, and $H_{1}(t)=\sin (6 t+20)$, $H_{2}(t)=\sin (4 t)$. Spectra for the three functions are shown in Fig. Alv-vii. However, the banding of the predictors is determined by the spectral bands of the predictand. Therefore $G_{1}(t)$ and $H_{2}(t)$ do not enter the procedure, and only the matching spectral information is used to make the forecast. Thus, $G_{2}(t)$ is used to forecast $F_{1}(t)$, and $H_{1}(t)$ is used to forecast $F_{2}(t)$. The forecast $\left[F^{\prime \prime}(t)\right]$ is shown in Fig. A1viii. It is clear that in this very simple case that the forecast is perfect (correlation of unity). If we were considering real geophysical time series, the spectral separation could not have been accomplished using classical Fourier transforms. The more general method is described in Fig. 6 and the section titled "Statistical scheme."

\section{REFERENCES}

ADPC, 2002: Application of climate forecasts in the agriculture sector. Climate Forecasting Applications in
Bangladesh Project Rep. 3, Asian Disaster Preparedness Center, Bangkok, Thailand, 29 pp.

Arkin, P. A., and B. N. Meisner, 1987: The relationship between large-scale convective rainfall and cold cloud over the Western Hemisphere during 1982-84. Mon. Wea. Rev., 115, 51-74.

Bamzai, A. S., and J. Shukla, 1999: Relation between Eurasian snow cover, snow depth, and the Indian summer monsoon: An observational study. J. Climate, 12, 3117-3132.

Clark, C. O., J. E. Cole, and P. J. Webster, 2000: SST and Indian summer rainfall: Predictive relationships and their decadal variability. J. Climate, 13, 2503-2519.

Dickson, R. R., 1984: Eurasian snow cover versus Indian monsoon rainfall-An extension of the HahnShukla results. J. Climate Appl. Meteor., 23, 171-173.

Ferranti, L., J. M. Slingo, T. N. Palmer, and B. J. Hoskins, 1997: Relations between the interannual and intraseasonal monsoon variability as diagnosed from AMIP integrations. Quart. J. Roy. Meteor. Soc., 123, 1323-1357.

Flatau, M. K., P. J. Flatau, and D. Rudnick, 2001: The dynamics of double monsoon onsets. J. Climate, 14, 4139-4146.

Friedman, J. H., 1991: Multivariate adaptive regression splines. Ann. Stat., 19, 1-67.

Gadgil, S., 1996: Climate change and agriculture-An Indian perspective. Climate Variability and Agriculture, Y. R. Abool, S. Gadgil, and G. B. Pant, Eds., Narosa, 1-18.

— , P. R. Seshagiri, and S. Sridhar, 1999: Modelling impact of climate variability on rainfed groundnut. Curr. Sci., 76, 557-569.

—_, — and K. Narahari Rao, 2002: Use of climate information for farm-level decision making: Rainfed groundnut in southern India. Agric. Syst., 74, 431457.

Goswami, B. N., and R. S. A. Mohan, 2001: Intraseasonal oscillations and interannual variability of the Indian summer monsoon. J. Climate, 14, 1180-1198.

Gruber, A., and A. F. Krueger, 1984: The status of the NOAA outgoing longwave radiation data set. Bull. Amer. Meteor. Soc., 65, 958-962.

Hahn, D., and J. Shukla, 1976: An apparent relationship between Eurasian snow cover and Indian monsoon rainfall. J. Atmos. Sci., 33, 2461-2462.

Harzallah, A., and R. Sadourny, 1997: Observed lead-lag relationships between Indian summer monsoon and some meteorological variables. Climate Dyn., 13, 635-648.

Hastenrath, S., 1986: Tropical climate prediction: A progress report 1985-90. Bull. Amer. Meteor. Soc., 67, 819-825. 
1987: On the prediction of India summer rainfall anomalies. J. Climate Appl. Meteor., 26, 847-857.

Hendon, H. H., and M. L. Salby, 1996: Planetary-scale circulations forced by intraseasonal variations of observed convection. J. Atmos. Sci., 53, 1751-1758.

—, C. D. Zhang, and J. D. Glick, 1999: Interannual variation of the Madden-Julian oscillation during austral summer. J. Climate, 12, 2538-2550.

Joyce, R., and P. A. Arkin, 1997: Improved estimates of tropical and subtropical precipitation using the GOES precipitation index. J. Atmos. Oceanic Technol., 14, 997-1011.

Kalnay, E., and Coauthors, 1996: The NCEP/NCAR 40Year Reanalysis Project. Bull. Amer. Meteor. Soc., 77, 437-471.

Kiladis, G. N., and K. M. Weickmann, 1992: Circulation anomalies associated with tropical convection during northern winter. Mon. Wea. Rev., 120, 1900 1923.

Kripalani, R. H., S. V. Singh, and P. A. Arkin, 1991: Large scale features of rainfall and outgoing longwave radiation over Indian and adjoining regions. Contrib. Atmos. Phys., 64, 159-168.

Krishnakumar, V., and K.-M. Lau, 1998: Possible role of symmetric instability in the onset and abrupt transitions of the Asian monsoon. J. Meteor. Soc. Japan, 76, 363-383.

Krishnamurti, T. N., M. Subramaniam, D. K. Oosterhof, and G. Daughenbaugh, 1990: Predictability of lowfrequency modes. Meteor. Atmos. Phys., 44, 63-83.

,,-- G. Daughenbaugh, D. K. Oosterhof, and J. H. Xue, 1992: One-month forecasts of wet and dry spells of the monsoon. Mon. Wea. Rev., 120, 1191-1223.

— S. O. Han, and V. Misra, 1995: Prediction of the wet and dry spells of the Australian monsoon. Int. J. Climatol., 15, 753-771.

Kumar, K. K., B. Rajagopalan, and M. A. Cane, 1999: On the weakening relationship between the Indian monsoon and ENSO. Science, 284, 2156-2159.

Lawrence, D. M., and P. J. Webster, 2001: Interannual variability of intraseasonal convection and the Asian monsoon. J. Climate, 14, 2910-2922.

— , and _ 2002: The boreal summer intraseasonal oscillation and the south Asian monsoon. J. Atmos. Sci., 59, 1593-1606.

Leonard, T., and J. S. J. Hsu, 1999: Bayesian Methods: An analysis for Statisticians and Interdisciplinary Researchers. Cambridge Series in Statistical and Probabilistic Mathematics, Cambridge University Press, 333 pp.

Liebmann, B., and C. A. Smith, 1996: Description of a complete (interpolated) outgoing longwave radiation dataset. Bull. Amer. Meteor. Soc., 77, 1275-1277.
Lo, F., and H. H. Hendon, 2000: Empirical prediction of the Madden-Julian oscillation. Mon. Wea. Rev., 128, 2528-2543.

Madden, R. A., and P. R. Julian, 1972: Description of global-scale circulation cells in the Tropics with a 4050 day period. J. Atmos. Sci., 29, 1109-1123.

$\longrightarrow$, and —-, 1994: Observations of the 40-50 day tropical oscillation: A review. Mon. Wea. Rev., 122, 814-837.

Mo, K. C., 2001: Adaptive filtering and prediction of intraseasonal oscillations. Mon. Wea. Rev., 129, 802817.

Murakami, T., 1976: Cloudiness fluctuations during the summer monsoon. J. Meteor. Soc. Japan, 54, 175-181.

Palmer, T. N., 1994: Chaos and the predictability in forecasting the monsoon. Proc. Indian Natl. Sci. Acad., 60A, 57-66.

Parthasarathy, B., A. A. Munot, and D. R. Kothawale, 1995: Monthly and seasonal rainfall series for all-India homogeneous regions and meteorological subdivisions: 1871-1994. Research Rep. RR-065, Indian Institute of Tropical Meteorology, Pune, India, $113 \mathrm{pp}$.

Poveda, G., C. Hoyos, J. F. Meja, L. F. Cavajal, O. J. Mesa, A. Cuartas, and J. Barco, 2001: Prediccin no lineal de los caudales medias mensuales del rio nare. $A v$. Recursos Hidraul., 8, 65-76.

Randall, D., M. Khairoutdinov, A. Arakawa, and W. Grabowski, 2003: Breaking the cloud parameterization deadlock. Bull. Amer. Meteor. Soc., 84, 15471564.

Reynolds, R. W., and D. C. Marsico, 1993: An improved real-time global sea surface temperature analysis. $J$. Climate, 6, 114-119.

Selvaraju, R., 2003: Impact of the El Nino Southern Oscillation on Indian foodgrain production. Int. J. Climatol., 23, 187-206.

Sengupta, D., B. N. Goswami, and R. Senan, 2001: Coherent intraseasonal oscillations of ocean and atmosphere during the Asian summer monsoon. Geophys. Res. Lett., 28, 4127-4130.

Shukla, J., 1987: Long-range forecasting of monsoon. Monsoons, J. Fein and P. L. Stephens, Eds., John Wiley and Sons, 523-548.

— and long range forecasting of the summer monsoon rainfall over India. Mon. Wea. Rev., 111, 1830-1837.

— the summer monsoon rainfall over India. Mon. Wea. Rev., 115, 695-703.

Sikka, D., and S. Gadgil, 1980: On the maximum cloud zone and the ITCZ over Indian longitudes during the southwest monsoon. Mon. Wea. Rev., 108, 18401853. 
Singh, S. V., R. H. Kripalani, and D. R. Sikka, 1992: Interannual variability of the Madden-Julian oscillation in Indian summer monsoon rainfall. J. Climate, 5, 973-978.

Slingo, J. M., K. R. Sperber, and J. S. Boyle, 1996: Intraseasonal oscillations in 15 atmospheric general circulation models: Results from an AMIP diagnostic subproject. Climate Dyn., 12, 325-357.

Sperber, K. R., J. M. Slingo, and H. Annamalai, 2000: Predictability and the relationship between subseasonal and interannual variability during the Asian summer monsoon. Quart. J. Roy. Meteor. Soc., 126, 2545-2574.

—- and Coauthors, 2001: Dynamical seasonal predictability of the Asian summer monsoon. Mon. Wea. Rev., 129, 2226-2248.

Subbiah, A., Ed., 2004: Initial report on the Indian monsoon drought of 2002. Asian Disaster Preparedness Center, Bangkok, Thailand, 29 pp.

Tomas, R., and P. J. Webster, 1997: On the location of the intertropical convergence zone and nearequatorial convection: The role of inertial instability. Quart. J. Roy. Meteor. Soc., 123, 1445-1482.

— J. R. Holton, and P. J. Webster, 1999: On the theory of the location of convection in strong crossequatorial pressure gradient flows. Quart. J. Roy. Meteor. Soc., 125, 1107-1127.

Torrence, C., and G. P. Compo, 1998: A practical guide to wavelet analysis. Bull. Amer. Meteor. Soc., 79, 6178.

—, and P. J. Webster, 1999: Interdecadal changes in the ENSO-monsoon system. J. Climate, 12, 26792690.

von Storch, H., and J. Xu, 1990: Principal oscillation pattern analysis of the 30- to 60-day oscillation in the tropical troposphere. Climate Dyn., 4, 175-190.

— and F. W. Zwiers, 1999: Statistical Analysis in Climate Research. Cambridge University Press, 484 pp.

Waliser, D. E., C. Jones, J. K. Schemm, and N. E. Graham, 1999: A statistical extended-range tropical forecast model based on the slow evolution of the Madden-Julian oscillation. J. Climate, 12, 19181939.

—-, and Coauthors, 2003a: AGCM simulations of intraseasonal variability associated with the Asian summer monsoon. Climate Dyn., 21, 423-446.
, K.-M. Lau, W. Stern, and C. Jones, 2003b: Potential predictability of the Madden-Julian oscillation. Bull. Amer. Meteor. Soc., 84, 33-50.

- S. Schubert, A. Kumar, K. Weickmann, and R. Dole, 2003c: Modeling, simulation, and forecasting of subseasonal variability. Technical Report Series on Global Modeling and Data Assimilation, NASA/CP 2003-104606, Vol. 25, 62 pp. [Available online at http://terra.msrc.sunysb.edu/other/subseas. workshop2.pdf.]

— W. Wtern, S. Schubert, and K. M. Lau, 2003d: Dynamical predictability of intraseasonal variability associated with the Asian summer monsoon. Quart. J. Roy. Meteor. Soc., 129, 2897-2925.

Walker, G. T., 1923: Correlations in seasonal variations of weather. VIII, A preliminary study of world weather. Mem. Indian Meteor. Dept., 24, 75-131.

Wang, B., and H. Rui, 1997: Synoptic climatology of transient tropical intraseasonal convective anomalies. Meteor. Atmos. Phys., 74, 1975-1985.

—, P. J. Webster, and H. Teng, 2004: Antecedents of active-break Indian monsoon unraveled by satellites. Geophys. Res. Lett., submitted.

Webster, P. J., 1983: Mechanisms of monsoon transition: Surface hydrology effects. J. Atmos. Sci., 40, 2110-2124.

—, T. Palmer, M. Yanai, R. Tomas, V. Magana, J. Shukla, and A. Yasunari, 1998: Monsoons: Processes, predictaiblity and the prospects for prediction. J. Geophys. Res., 103, 14 451-14 510.

— Bull. Amer. Meteor. Soc., 83, 1603-1630.

Wheeler, M., and K. M. Weickmann, 2001: Real-time monitoring and prediction of modes of coherent synoptic to intraseasonal tropical variability. Mon. Wea. Rev., 129, 2677-2694.

WMO, 2001: Report of the CAS Working Group on Tropical Meteorology Research. Tropical Meteorology Research Programme Rep. Series, TMRP, 66, $32 \mathrm{pp}$.

Yasunari, T., 1979: Cloudiness fluctuations associated with the Northern Hemisphere summer monsoon. J. Meteor. Soc. Japan, 57, 227-242.

- 1980: A quasi-stationary appearance of the 3040 day period in the cloudiness fluctuations during the summer monsoon over India. J. Meteor. Soc. Japan, 58, 225-229. 